NASA Technical Memorandum 4743

\title{
Modified Fully Utilized Design (MFUD) Method for Stress and Displacement Constraints
}

Surya Patnaik

Ohio Aerospace Institute

Brook Park, Ohio

Atef Gendy, Laszlo Berke, and Dale Hopkins

Lewis Research Center

Cleveland, Ohio

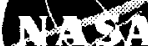

National Aeronautics and

Space Administration

Office of Management Scientific and Technical Information Program

1997 



\title{
Modified Fully Utilized Design (MFUD) Method for Stress and Displacement Constraints
}

\author{
Surya N. Patnaik \\ Ohio Aerospace Institute \\ Cleveland, Ohio 44142 \\ Atef S. Gendy*, Laszlo Berke, and Dale A. Hopkins \\ National Aeronautics and Space Administration \\ Lewis Research Center \\ Cleveland, Ohio 44135
}

\section{Summary}

The traditional fully stressed method performs satisfactorily for stress-limited structural design. When this method is extended to include displacement limitations in addition to stress constraints, it is known as the fully utilized design (FUD). Typically, the FUD produces an overdesign, which is the primary limitation of this otherwise elegant method. We have modified FUD in an attempt to alleviate the limitation. This new method, called the modified fully utilized design (MFUD) method, has been tested successfully on a number of problems that were subjected to multiple loads and had both stress and displacement constraints. The solutions obtained with MFUD compare favorably with the optimum results that can be generated by using nonlinear mathematical programming techniques. The MFUD method appears to have alleviated the overdesign condition and offers the simplicity of a direct, fully stressed type of design method that is distinctly different from optimization and optimality criteria formulations. The MFUD method is being developed for practicing engineers who favor traditional design methods rather than methods based on advanced calculus and nonlinear mathematical programming techniques. The Integrated Force Method (IFM) was found to be the appropriate analysis tool in the development of the MFUD method. In this paper, the MFUD method and its optimality are examined along with a number of illustrative examples.

\section{Introduction}

The fully stressed design FSD method (ref. 1) which is based on a simple stress-ratio approach, is an elegant design tool that is popular across the civil, mechanical, and aerospace engineering industries. However, the FSD is useful only for stresslimited designs; it cannot properly handle the displacement limitations that have become typical design constraints of modern structures. When FSD is extended to handle situations with both stress and displacement constraints, it is called the fully utilized design (FUD). Two steps that are required to obtain the FUD are (1) generate the FSD for stress constraints only, and (2) then uniformly prorate it to obtain the FUD. The constant proration factor is obtained to satisfy the single most infeasible displacement constraint. Although the FUD thus obtained is feasible, it can be an overdesign, which is the primary limitation of the otherwise elegant design method. At present, a direct design method to efficiently handle both stress and displacement constraints is not available. Moreover, sustained effort to improve FUD has not been reported in the literature. Instead of developing a simpler tool, the designers of the 1960's were complicating the approach by applying nonlinear mathematical programming techniques of operations research (refs. 2 to 8 ) and Langrangian-based optimality criteria methods (refs. 9 to 11). Some success has been achieved in design optimization; however, these techniques can be computationally intensive, and convergence difficulties are frequently encountered, even for modest problems (refs. 12 and 13). Despite these limitations, design optimization is popular in academia and is being improved and promoted for industrial applications, especially since there is no alternate design tool that effectively handles both stress and displacement constraints. These optimization methods, to a certain extent, have yet to mature and become a standardized design tool for utilization by practicing engineers. Imagine the distress of these engineers at finding that design has been made more complex by the introduction of advanced calculus and variational techniques, without a comparable benefit. Although design optimization is analytically elegant, a simpler alternative, such as FSD/FUD, need not be abondoned, especially for routine and practical engineering design. Further research and development needs to be done on direct design methods that do not employ mathematical programing techniques.

This paper outlines the development of a simple FSD/FUD type design tool that can handle both stress and displacement constraints simultaneously. The proposed design tool is called the modified fully utilized design (MFUD) method. In its

*National Research Council-NASA Research Associate at Lewis Research Center. 
simplicity, MFUD is comparable to the FUD method, yet it alleviates the overdesign limitation that has been associated with the traditional FUD technique. When tested on a number of problems, MFUD produced solutions comparable to those generated by design optimization methods. At this early stage, MFUD has been developed for two- and three-dimensional trusses with linked member areas as design variables. Successful completion of the MFUD method for stress and displacement constraints will eventually open up an avenue for the extension of this method to other types of structures and constraints. The proponents of optimization methods can also benefit from MFUD by using it to initiate optimization iterations, thereby alleviating some of the computational burden of such methods.

In this paper the theoretical basis of MFUD is developed and illustrated for two examples. A summary of MFUD results, along with optimization solutions for several examples, is included. The Integrated Force Method (IFM, refs. 14 to 16) is shown to be an appropriate analysis tool for deriving the MFUD formulas (see appendix A). An analytical examination of the optimality of FSD and FUD (see appendix B) is followed by a discussion.

\section{Design Optimization Problem}

Standard nonlinear programming terminology is used to formulate the design problem for trusses because solutions obtained by the MFUD method are compared with optimization results. The areas of truss members that can be linked for practical purposes are considered to be design variables. The structures are subjected to multiple load conditions, and constraints are imposed simultaneously on both stresses and displacements. The number of stress and displacement constraints are denoted by $J_{s}$ and $J_{d}$, respectively, with the total number of constraints being $m=J_{s}+J_{d}$. The $J_{s}$ number of stress constraints can be specified as

$$
g_{j}=\left|\frac{\sigma_{j}}{\sigma_{j o}}\right|-1.0 \leq 0 \quad j=1,2, \ldots, J_{s}
$$

where $\sigma_{j}$ is the stress in the $j$ th member and $\sigma_{j o}$ is its permissible value.

Likewise, the $J_{d}$ number of displacement constraints can be written as

$$
g_{J_{s}+j}=\left|\frac{X_{j}}{X_{j o}}\right|-1.0 \leq 0 \quad j=1,2, \ldots, J_{d}
$$

where $X_{j}$ is the $j$ th displacement component and $X_{j o}$ is its permissible value. The stress and displacement behavior constraints are feasible provided that $g_{k} \leq \mathbf{0}$.

For a truss with $n$ members, the weight can be considered as the objective function for design optimization, and it can be written as

$$
W(\{A\})=\sum_{i=1}^{n} \ell_{i} \rho_{i} A_{i}
$$

where $\ell_{i}, \rho_{i}$, and $A_{i}$ are the length, density, and area of the $i$ th member of the truss, respectively. The computer code automatically modifies equation (3) for linked design variables, but that modification is not elaborated here.

\section{Fully Utilized Design}

The traditional FUD can be obtained in two steps: (1) generation of an FSD and (2) uniform proration of the FSD to obtain the FUD.

An FSD for stress constraints only is generated iteratively by using a stress-ratio technique that can be written as

$$
A_{i}^{\sigma, k+1}=A_{i}^{\sigma, k} R_{\mathrm{\sigma} i} \quad i=1,2, \ldots, n
$$

where $A_{i}{ }^{\sigma, k}$ is the area of the $i$ th member at the $k$ th iteration (unit member areas can be used to initiate the iterations). The factor $R_{s i}$ for the $i$ th design variable is determined as

$$
R_{\sigma i}=\frac{\max \left(\sigma_{1 i}, \sigma_{2 i}, \ldots, \sigma_{L i}\right)}{\sigma_{i o}}
$$

where $\sigma_{L i}$ represents stress in member $i$ for load condition $L$, and $\sigma_{i o}$ represents the yield strength of member $i$. The converged solution of equation (4) is the FSD, designated as $\{A\}^{f s d}$. The FSD technique produces very fast convergence, usually in about 10 iterations, regardless of problem size.

Prorating the FSD to satisfy the maximum violated displacement constraint yields the traditional FUD for simultaneous stress and displacement constraints:

$$
\{A\}^{f u d}=\{A\}^{f s d}\left(1+g_{\max }\right)=\{A\}^{f s d}\left(\frac{X_{\max }}{X_{o}}\right)
$$

where $\{A\}^{f u d}$ is the vector of member areas; $g_{\max }$ is the value of the most violated displacement constraint; and $X_{\max }$ and $X_{o}$ are, respectively, the most violated and the allowable displacement values. The uniform proration factor $\left(1+g_{\max }\right)$ in equation (6) produces a feasible design. The FUD is likely to be overdesigned because all member areas have been increased by the same amount, and it has only one active displacement constraint.

The overdesign condition associated with the traditional FUD method can be illustrated by considering displacement constraints in the design of a five-bar truss (ref. 17) (see Numerical Examples, Example 3). The FUD method produces an optimum weight of $62.228 \mathrm{lb}$, whereas the optimality criteria method (OC) and the Sequential Unconstrained Minimization Technique (SUMT) yield 45.016 and $45.029 \mathrm{lb}$, respectively. In this example, the traditional FUD is 38 percent 
too heavy. For this problem, the proposed MFUD produced a weight of $44.817 \mathrm{lb}$; this is, respectively, 27.98, 0.44 , and 0.47 percent lighter than the weights produced by the FUD, $O C$, and SUMT methods. In the comparison of MFUD and optimization results, more than one optimizer is used because the performance of such methods can be problem-dependent, as is shown in reference 12 .

\section{Modified Fully Utilized Design}

The MFUD for simultaneous stress and displacement constraints can be obtained iteratively as follows:

Step (1): Identify the design variables to initiate the MFUD iterations. The first MFUD iteration can begin from the FSD $\{A\}^{f s d}$ (see eqs. (4) and (5)). For subsequent iterations, the areas for stress constraints can be obtained from

$$
A_{i}=\frac{\left(F_{i}\right)_{\max }}{\sigma_{i o}} \quad i=1,2, \ldots, n
$$

where $\left(F_{i}\right)_{\max }$ is the maximum force in the $i$ th member for all load conditions. This strategy ensures that the final MFUD is not biased towards the initial FSD, $\{A\}^{\text {fsd }}$.

Step (2): Identify the $v q$ number of violated displacement constraints $\{D\}=\left\{g_{v 1}, g_{v 2}, \ldots, g_{v q}\right\}$ for the design obtained in step (1).

Step (3): Update the design independently for each of the $v q$ violated displacement constraints contained in set $\{D\}$. (See the section Identification of Subset of Design Variables for a Violated Displacement Constraint, which shows how only a few design variables need to be updated to satisfy a violated displacement constraint.) Let the number of design variables that should be updated to satisfy a violated displacement constraint $g_{v r}$ be $q t$ (where $q t \leq n$ is the total number of design variables). The design update rule for the qith design variable, then, is

$$
A_{q i}^{v r}=A_{q i}^{f s d} \xi_{q i}^{v r}\left(1+g_{v r}\right) \quad q i=q 1, q 2, \ldots, q t
$$

where $\xi_{q i}^{v r} \leq 1.0$ is a weighted parameter (see the section Member Weighted Parameter). The design variables in the MFUD method are updated independently, in contrast to uniform proration in case of the traditional FUD method.

Step (4): Repeat step (3) for all $v q$ numbers of the violated displacement constraints to obtain $v q$ design subsets $\left(\{A\}^{v i}\right.$, for $v i=v 1, v 2, \ldots, v q$ ).

Step (5): Obtain the design update for the structure as the union of the $v q$ designs

$$
\{A\}^{m f u d}=\{A\}^{v 1} \bigcup\{A\}^{\nu 2} \cup \ldots \cup\{A\}^{v q}
$$

In the union process, the maximum value should be selected in case of member duplication.

Step (6): Repeat steps (1) to (5) until the design converges. The converged design will satisfy both stress and displacement constraints. A minimum weight condition is not explicitly imposed in the MFUD method; however, as will be shown for the examples solved, the weight of the design calculated by the MFUD method is very close to the optimum weight generated from optimization methods.

The number of design variables $q t$ that are associated with a violated displacement constraint and the weighted parameter $\xi_{q i}^{v r}$ (see eq. (8)) for each design variable can be easily identified when the IFM (refs. 14 to 16) is used as the analysis tool. The derivation of these two parameters is discussed next.

\section{Identification of a Subset of Design Variables for a Violated Displacement Constraint}

The subset of design variables $q t$ directly associated with a violated displacement $g_{v r}$ can be identified by examining the displacement-force relationship of IFM (see appendix A):

$$
\{X\}=[J][G]\{F\}
$$

where $\{X\}$ is the nodal displacement vector; $[J]=m$ rows of $[S]^{-\top}$, with $[S]$ being the governing IFM matrix; $[G]$ is the diagonal flexibility matrix; and $\{F\}$ is the internal force vector.

Because of the banded nature of matrices $[J]$ and $[G]$, for a single displacement component $X_{v r}$, equation (10) can be expanded as

$$
\begin{aligned}
X_{v r}=J_{v r, q 1}\left(\frac{\ell F}{E}\right)_{q 1}\left(\frac{1}{A_{q 1}^{v r}}\right) & +J_{v r, q 2}\left(\frac{\ell F}{E}\right)_{q 2}\left(\frac{1}{A_{q 2}^{v r}}\right) \\
& +\ldots+J_{v r, q t}\left(\frac{\ell F}{E}\right)_{q t}\left(\frac{1}{A_{q t}^{v r}}\right)
\end{aligned}
$$

The displacement component $X_{v r}$ is an explicit function of the subset of member areas referred to by indices $q 1, q 2, \ldots, q t$ in equation (11). Thus it is sufficient to update $q t$ design variables to satisfy the violated displacement constraint $g_{v r}$. Repeating this process identifies the critical members for each violated displacement constraint in set $\{D\}$.

\section{Member Weighted Parameter}

Instead of a uniform proration of all the design variables in the subset $q t$ for a violated constraint $g_{v r}$, individually weighted parameters are calculated for each design variable. The determination of individually weighted parameters is illustrated by the example of a 10-bar truss with a violated displacement 
constraint at its tip-node 3 along the transverse direction shown in figure 1. In this example, the violated tip displacement can be satisfied more effectively by increasing the area of the members nearest the support, such as members 1 and 5 in figure 1 , rather than the areas of those nearest the free end, such as members 3 and 10 . The weighted parameters bias the design in favor of support members 1 and 5 . These parameters can be selected by examining the sensitivities of the violated displacement constraints. The sensitivity of violated displacement $X_{v r}$ with respect to member area $A_{q i}^{v r}$ can be obtained via the IFM (ref. 19) (see appendix A) as

$$
\frac{\partial X_{v r}}{\partial A_{q i}^{v r}}=J_{v r, q i}\left(\frac{\ell F}{E}\right)_{q i}\left(\frac{1}{A_{q i}^{v r}}\right)^{2}
$$

For the 10-bar truss example, the displacement sensitivities for the four members (i.e., 1, 3, 5, and 10) are

$$
\frac{\partial X_{3}}{\partial A_{1}^{3}}=-1101.1 \quad \frac{\partial X_{3}}{\partial A_{5}^{3}}=-1059.2
$$

(members near the support)

$$
\frac{\partial X_{3}}{\partial A_{3}^{3}}=-67.7 \quad \frac{\partial X_{3}}{\partial A_{10}^{3}}=-336.8
$$

(members near the free end)

Equations (13) show that tip displacement is most sensitive to member areas 1 and 5 (near the support) and least sensitive to member area 3 (close to the tip). Overall, selecting a proration factor proportional to the sensitivities is adequate in satisfying

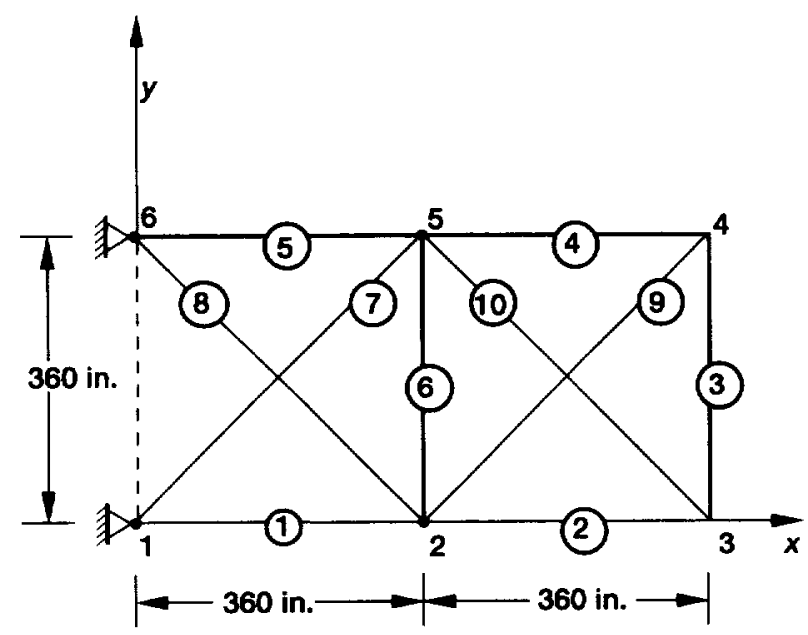

Figure 1.-Ten-bar truss (members are circled, nodes are not). a violated displacement constraint. The weighted parameter for the qith member area can be considered proportional to the negative gradient of the violated displacement $X_{v r}$ with respect to the member area $A_{q i}^{v r}$.

To safeguard against an overdesign, the weighted parameter should also be biased against long members with higher densities. Such a condition can be imposed from the gradient of the objective function $W$ with respect to member area $A_{q i}$ :

$$
\frac{\partial W}{\partial A_{q i}^{v r}}=\rho_{q i} \ell_{q i}
$$

The gradients of the objective function with respect to member areas $1,3,5$, and 10 (weight density for all members is $0.1 \mathrm{lb} / \mathrm{in}^{3}$ ) are

$$
\begin{gathered}
\rho_{1} \ell_{1}=36.0 \quad \rho_{5} \ell_{5}=36.0 \\
\text { (members near the support) } \\
\rho_{3} \ell_{3}=36.0 \quad \rho_{10} \ell_{10}=50.9 \\
\text { (members near the free end) }
\end{gathered}
$$

The weighted parameters can be considered inversely proportional to the gradient of the objective function.

Equations (12) and (14) can be combined and normalized to obtain the weighted parameter for the qith member area:

$$
\xi_{q i}^{v r}=\frac{\left(\frac{F}{\rho E\left(A^{v r}\right)^{2}}\right)_{q i} J_{v r, q i}}{\left.\max \left[\frac{F}{\rho E\left(A^{v r}\right)^{2}}\right)_{q m} J_{v r, q m}\right]} q m=q 1, q 2, \ldots, q t
$$

Although displacement and weight sensitivities are used in the derivation of equation (16), their calculations require trivial computational effort since the force vector $\{F\}$ and displacement coefficient matrix $[J]$ are available from analysis.

The final normalized weighted parameters for member areas $1,3,5$, and 10 of the 10-bar truss are

$$
\begin{gathered}
\xi_{1}^{3}=1.000 \quad \xi_{5}^{3}=0.962 \\
\text { (members near the support) } \\
\xi_{3}^{3}=0.059 \quad \xi_{10}^{3}=0.216 \\
\text { (members near the free end) }
\end{gathered}
$$


The area for the $q i$ th member of the $v r$ th violated displacement constraint can be updated by using the following formula:

$$
A_{q i}^{v r}=A_{q i}^{f s d} \xi_{q i}^{v r} t_{p}\left(1+g_{v r}\right) \quad q i=q 1, q 2, \ldots, q t
$$

The preceding equation is identical to equation (8) except for a step length $t_{p}<1$. The step length restricts member areas against rapid changes, for which the current analysis may no longer be valid. Default step lengths of $t_{p}=0.5$ for constraint violations exceeding unity (i.e., $g_{v r} \geq 1.0$ ) and $t_{p}=0.25 g_{v r}$ for other constraint violations were found satisfactory for most problems that have been solved.

The design obtained from equation (18) for the displacement component $X_{v r}$ is designated by the vector $\{A\}^{\mathrm{vr}}$. Likewise, areas can be obtained for all $v q$ of the violated displacement constraints contained in set $\{D\}$. The union of the $v q$ area subsets produces the area vector $\{A\}^{m f u d-x}$ for the truss. This area is then compared with the area for stress constraints (eq. (7)), and the final MFUD area $\{A\}^{m f u d}$ for a $k$ th iteration is obtained as

$$
A_{i}^{m f u d}=\max \left[A_{i}^{f s d}, A_{i}^{m f u d-x}\right] \quad i=1,2, \ldots, n
$$

The MFUD iterations are continued until convergence is achieved for both stress and displacement constraints.

\section{Numerical Examples}

The MFUD method was applied to a number of examples. The solutions are compared with those obtained by the traditional FUD method and with the optimum solutions generated by several optimization algorithms, such as SUMT (ref. 20); Sequential Quadratic Programming, SQP_IMSL (ref. 21); FD (ref. 22); and OC (ref. 9). The MFUD process is illustrated in detail here for the first two examples, a three-bar truss and a cantilevered truss, under a wide range of linked displacement constraints. For other examples, only the final results (summarized) are presented.

\section{Example 1: Three-Bar Truss}

A three-bar truss with Young's modulus $E=30000 \mathrm{ksi}$, density $=0.10 \mathrm{lb} / \mathrm{in} .^{3}$, and allowable strength $\sigma_{o}=20 \mathrm{ksi}$ is depicted in figure 2 . The truss is subjected to two load conditions; the first has two load components $\left(P_{x}=-50\right.$ kips and $P_{y}$ $=-100 \mathrm{kips})$, whereas the second has only one component $\left(P_{x}\right.$ $=50.0 \mathrm{kips}$ ). The truss has 10 behavior constraints, consisting of 3 stress and 2 displacement constraints (at node 1 , $X_{1 x} \leq 0.2$ in. and $X_{1 y} \leq 0.05 \mathrm{in}$.) for each load case. The optimum solution for the three-bar truss was generated by using three

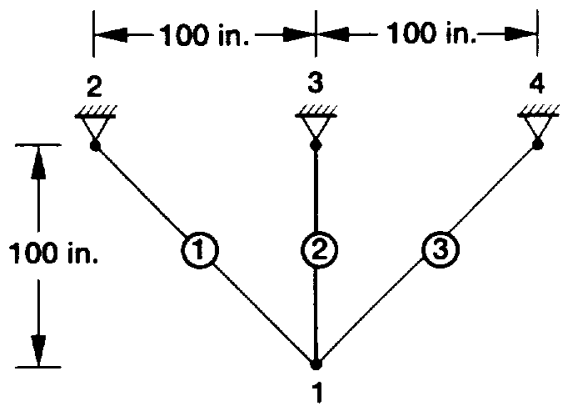

Figure 2.-Three-bar truss (members are circled, nodes are not).

optimizers: SUMT, FD, and OC. Initial designs of unity were used for all design methods. The SUMT and FD optimizers converged to optimum weights of 100.07 and $99.95 \mathrm{lb}$, respectively, whereas the OC optimizer generated a slight overdesign, reflected in a weight of $101.33 \mathrm{lb}$. The FSD (for stress constraints only), as determined by the stress-ratio technique, gave $A_{1}=1.182, A_{2}=2.504$, and $A_{3}=3.533$ in $^{2}$ The FSD violated one displacement constraint $\left(X_{1 y}\right)$ under the first load condition. The traditional FUD, which satisfied the violated constraint, gave $A_{1}=1.574, A_{2}=3.336$, and $A_{3}=4.706$ in. $^{2}$ The FUD had only one active displacement constraint and was overdesigned by 22.2 percent, with a weight of $122.182 \mathrm{lb}$.

The MFUD for the truss converged to an optimum weight of $99.97 \mathrm{lb}$ (see table I). The MFUD results compare well with those generated by SUMT, FD, and OC optimizers (see table II). The MFUD, SUMT, and FD methods yielded identical numbers of active stress and displacement constraints; however, the OC method produced only one active stress constraint (a one-fifth of 1-percent constraint thickness is considered active). Overall, the MFUD method performed satisfactorily for this problem.

The convergence characteristics of MFUD, along with those for SUMT, FD, and $O C$ are depicted in figure 3. MFUD converged rapidly and monotonically in 24 reanalysis cycles that included the 12 reanalyses to obtain the FSD. The convergence characteristics for FD were rather uneven, requiring 47 reanalysis cycles to reach the optimum solution. SUMT and OC solutions required 62 and 80 reanalysis cycles, respectively.

TABLE I--THREE-BAR TRUSS RESULTS FOR A FEW MFUD ITERATIONS

\begin{tabular}{|l|c|r|r|r|r|}
\hline Iterations & $\begin{array}{c}\text { Weight, } \\
\text { lb }\end{array}$ & \multicolumn{3}{|c|}{ Member area, in. } & \multicolumn{2}{c|}{$\begin{array}{c}\text { Violated } \\
\text { constraint, } \\
\mathrm{X}_{\mathrm{ly}}\end{array}$} \\
\cline { 2 - 5 } & & $\mathrm{A}_{1}$ & $\mathrm{~A}_{2}$ & $\mathrm{~A}_{3}$ & \\
\hline 0 & 91.714 & 1.182 & 2.502 & 3.533 & 0.3322 \\
1 & 93.770 & 1.179 & 2.710 & 3.534 & .2626 \\
2 & 94.669 & 1.149 & 3.042 & 3.445 & .2131 \\
10 & 99.000 & 1.100 & 3.673 & 3.330 & .0329 \\
14 (final) & 99.966 & 1.088 & 3.841 & 3.265 & .0009 \\
\hline
\end{tabular}

${ }^{2}$ Represents FSD. 
TABLE II--THREE-BAR TRUSS: RELATIONSHIP OF ACTIVE STRESS AND DISPLACEMENT CONSTRAINTS TO OPTIMUM DESIGN

\begin{tabular}{|l|c|c|c|c|c|c|c|}
\hline $\begin{array}{l}\text { Design } \\
\text { method }\end{array}$ & $\begin{array}{c}\text { Weight, } \\
\mathrm{lb}\end{array}$ & \multicolumn{3}{|c|}{ Member area, in. ${ }^{2}$} & \multicolumn{2}{c|}{$\begin{array}{c}\text { Number of active } \\
\text { constraints }\end{array}$} & $\begin{array}{c}\text { Number of } \\
\text { reanalyses }\end{array}$ \\
\cline { 3 - 7 } & & $\mathrm{A}_{1}$ & $\mathrm{~A}_{2}$ & $\mathrm{~A}_{3}$ & Stress & Displacement & \\
\hline MFUD & 99.97 & 1.088 & 3.841 & 3.265 & 2 & 1 & 24 \\
FUD & 122.18 & 1.574 & 3.336 & 4.706 & - & 1 & 10 \\
SUMT & 100.07 & 1.088 & 3.848 & 3.267 & 2 & 1 & 62 \\
FD & 99.95 & 1.092 & 3.855 & 3.250 & 2 & 1 & 47 \\
OC & 101.33 & 1.053 & 3.913 & 3.345 & 1 & - & 80 \\
\hline
\end{tabular}

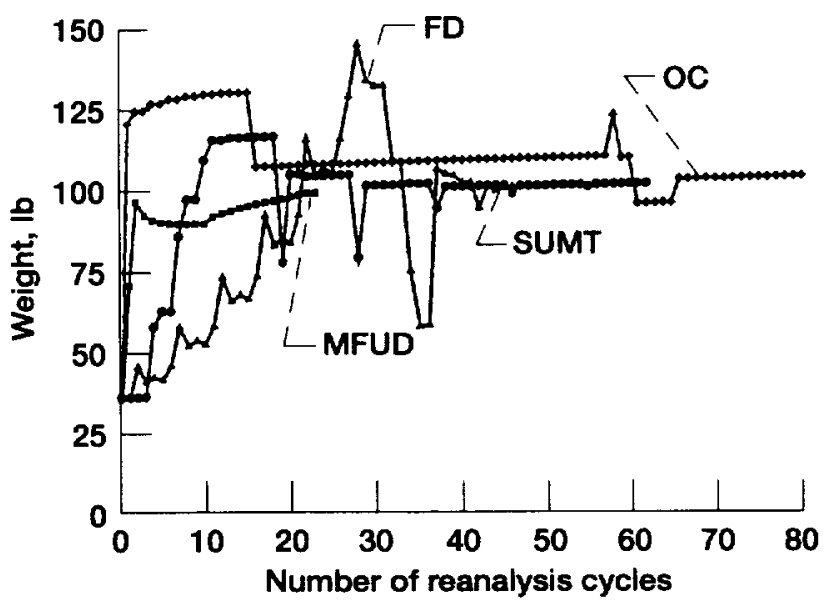

Figure 3.-Convergence history of three-bar truss.

\section{Example 2: Cantilevered Truss With Stress and a Sequence of Displacement Constraints}

The 10-bay cantilevered steel truss shown in figure 4 is the second example. The truss has 22 nodes and 50 members. It is made of a material with a Young's modulus $E=30.0 \times 10^{6} \mathrm{psi}$, a weight density $\rho=0.289 \mathrm{lb} / \mathrm{in}^{3}$, and an allowable strength $\sigma_{o}=20 \times 10^{3} \mathrm{psi}$. The truss is subjected to two load conditions. The first is a single load of 100 kips at node 22 along the negative $y$-direction. The second is a load of 10 kips applied at all nodes along the top chord (i.e., node numbers $4,6, \ldots, 22$; see fig. 4). Stress constraints are considered for all 50 bars -100 stress constraints for both load conditions. Displacements along the transverse direction are specified at the free end (nodes 21 and 22) as well as at the center span (node 11). The magnitude of the center span displacement is specified to be a quarter of the tip displacement. The tip displacement is a parameter that changes, ranging in magnitude between 0.05 and 1.5 in. The stress constraints dominate the design only when the magnitude of the tip displacement exceeds $1.4 \mathrm{in}$. When displacements are less than $1.4 \mathrm{in}$., both stress and displacement become active constraints. Constraint activities of final designs obtained with MFUD, FUD, FD, and SQP_IMSL are given in table III for three design situations (tip displacements of 0.5 , 1.0 , and $1.5 \mathrm{in}$.).

Optimum weights obtained by MFUD, FUD, and FD methods were normalized with respect to the weight obtained by the SQP_IMSL method, which performed best for the entire displacement range $0.05 \leq \delta \leq 1.5$ (see fig. 5). Notice the following observations from figure 5 and table III. The MFUD method performs adequately for the entire displacement range, with the error not exceeding 2 percent of the optimum solution generated by SQP_IMSL. In contrast, the maximumerror in the weight obtained by the FUD method was about 26 percent. When stresses dominated the design (i.e., displacement values exceeded $1.4 \mathrm{in}$.), the FD optimizer produced a 4-percent overdesign, but MFUD, FUD, and SQP_IMSL converged to the correct optimum. In other words, the traditional FUD method exhibited an overdesign condition when the displacements were active constraints, but converged to the correct solutions when the displacements became passive constraints, that is, at the FSD condition. Optimizers SQP_IMSL and FD, and the MFUD method provided the same number of active displacement constraints for the entire displacement range (see table III). The MFUD method, however, produced a greater number of active

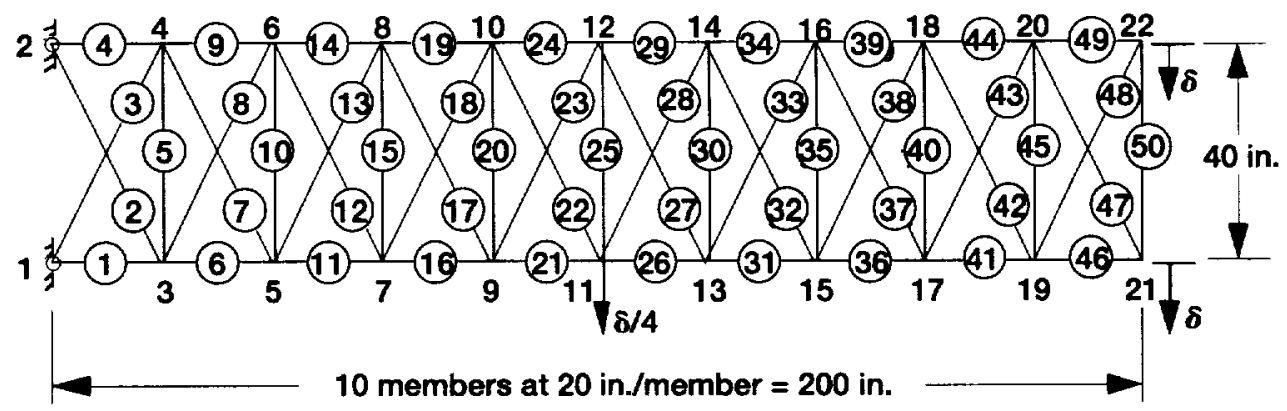

Figure 4.-Cantilever truss (members are circled, nodes are not). Displacement limitation $\delta$ at center is one-fourth of that at the end. 
TABLE III -CANTILEVERED TRUSS RELATIONSHIP OF ACTIVE CONSTRANTS TO OPTIMUM WEIGHT OF TRUSS AT VARIOUS DISPLACEMENTS

\begin{tabular}{|c|c|c|c|}
\hline \multirow[t]{2}{*}{ Design method } & \multicolumn{2}{|c|}{$\begin{array}{c}\text { Number of active } \\
\text { constraints }\end{array}$} & \multirow[t]{2}{*}{$\begin{array}{l}\text { Weight, } \\
\text { klb }\end{array}$} \\
\hline & Stress & Displacement & \\
\hline \multicolumn{4}{|c|}{ At $d=0.5$ in. $^{2}$} \\
\hline $\begin{array}{l}\text { MFUD } \\
\text { FUD } \\
\text { FD } \\
\text { SQP_IMSL }\end{array}$ & $\begin{array}{l}4 \\
- \\
- \\
2\end{array}$ & $\begin{array}{l}2 \\
1 \\
2 \\
2\end{array}$ & $\begin{array}{l}4.701 \\
5.855 \\
4.669 \\
4.618\end{array}$ \\
\hline \multicolumn{4}{|c|}{ At $\mathrm{d}=1.0$ in. } \\
\hline $\begin{array}{l}\text { MFUD } \\
\text { FUD } \\
\text { FD } \\
\text { SQP_IMSL }\end{array}$ & $\begin{array}{c}23 \\
- \\
20 \\
21\end{array}$ & $\begin{array}{l}1 \\
1 \\
1 \\
1\end{array}$ & $\begin{array}{l}2.521 \\
2.928 \\
2.540 \\
2.538\end{array}$ \\
\hline \multicolumn{4}{|c|}{ At d $=1.5$ in. } \\
\hline $\begin{array}{l}\text { MFUD } \\
\text { FUD } \\
\text { FD } \\
\text { SQP_IMSL }\end{array}$ & $\begin{array}{l}44 \\
44 \\
25 \\
41\end{array}$ & $\begin{array}{l}- \\
- \\
-\end{array}$ & $\begin{array}{l}2.196 \\
2.196 \\
2.279 \\
2.191\end{array}$ \\
\hline
\end{tabular}

${ }^{\mathrm{a}} \mathrm{d}=$ tip displacement.

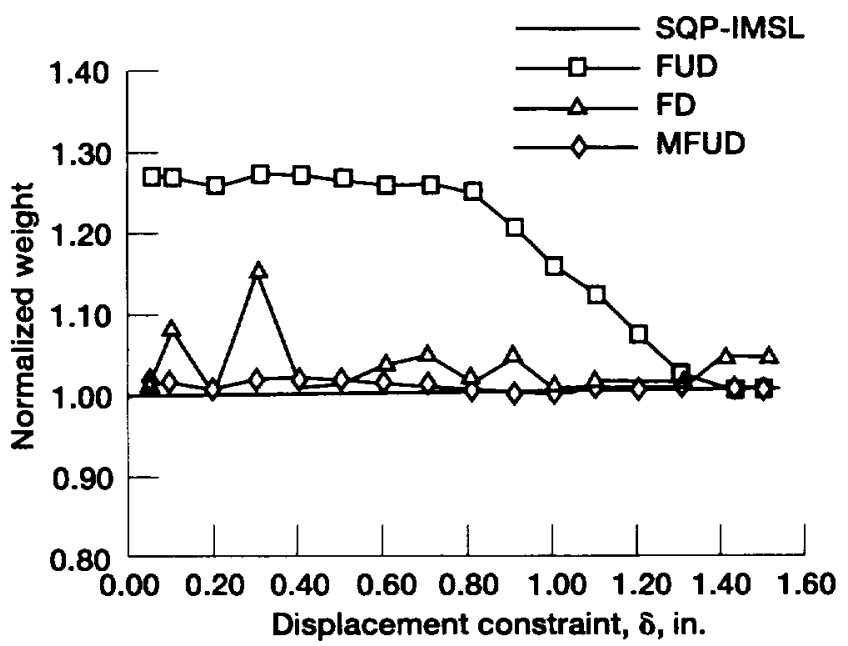

Figure 5.-Weight normalized with respect to SQP-IMSL as a function of displacement constraints of a cantilever truss

stress constraints. For example, when the displacement limitation was 0.5 in., the number of stress constraints produced by MFUD, SQP_IMSL, and FD were 4, 2, and 0, respectively. For this problem, the MFUD method produced results equal or superior to the FUD method for all three displacement limitations $(0.5,1.0$, and 1.5 in.), as shown in table III. A comparison of the weights obtained by the MFUD method and the SQP_IMSL optimizer shows that SQP_IMSL outperforms MFUD by 1.8 percent at a displacement of 0.5 in. and by 0.2 percent at a displacement of $1.5 \mathrm{in}$. When the displacement value is 1.0 in., the MFUD weight is better than the SQP_IMSL weight by 0.69 percent.

\section{Example 3: Five-Bar Truss}

The five-bar aluminum truss (refs. 17 and 18) depicted in figure 6 was subjected to a single load and had a single displacement constraint in the transverse direction at node 4 . The design parameters obtained by the four methods are summarized in table IV. For this truss, MFUD produced results slightly superior to SUMT and OC. The traditional FUD produced a design that was 39 percent too heavy.

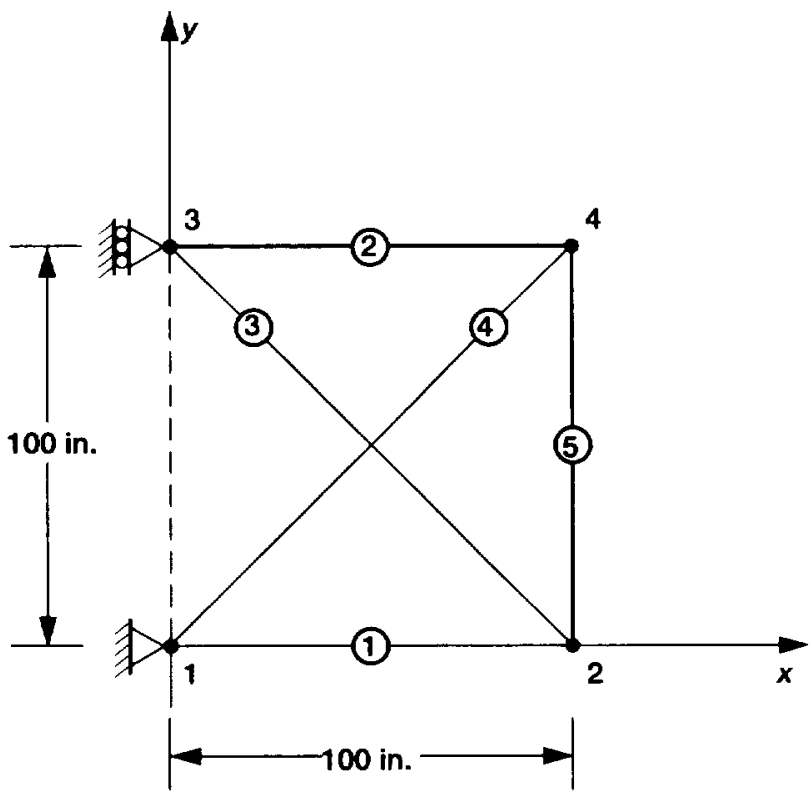

Figure 6.-Five-bar truss (members are circled, nodes are not).

TABLE IV.- FIVE-BAR TRUSS DESIGN
\begin{tabular}{|l|r|r|r|r|}
\hline \multicolumn{1}{|c|}{ RESULS } \\
\hline Results & MFUD & FUD & SUMT & OC \\
\hline Optimum weight, lb & 44.817 & 62.228 & 45.029 & 45.016 \\
Member area, in. ${ }^{2}$ & & & & \\
$\mathrm{~A}_{1}$ & 0.001 & 1.068 & 0.001 & 0.001 \\
$\mathrm{~A}_{2}$ & 1.475 & & 1.501 & 1.499 \\
$\mathrm{~A}_{3}$ & 0.001 & & 0.001 & 0.001 \\
$\mathrm{~A}_{4}$ & 2.124 & & 2.119 & 2.120 \\
$\mathrm{~A}_{5}$ & 0.001 & $\downarrow$ & 0.001 & 0.001 \\
Active displacement & & & & \\
constraints & 1 & 1 & 1 & 1 \\
\hline
\end{tabular}

\section{Example 4: Tapered Five-Bar Truss}

The tapered five-bar steel truss (ref. 23) shown in figure 7 was subjected to two load conditions and had five stress and two displacement constraints for each load condition. The attributes of the designs generated by the four methods are summarized in table V; all the optimum weights are in good agreement. The MFUD method produced five active constraints, whereas SUMT and $O C$ produced three and four active constraints, respectively. 


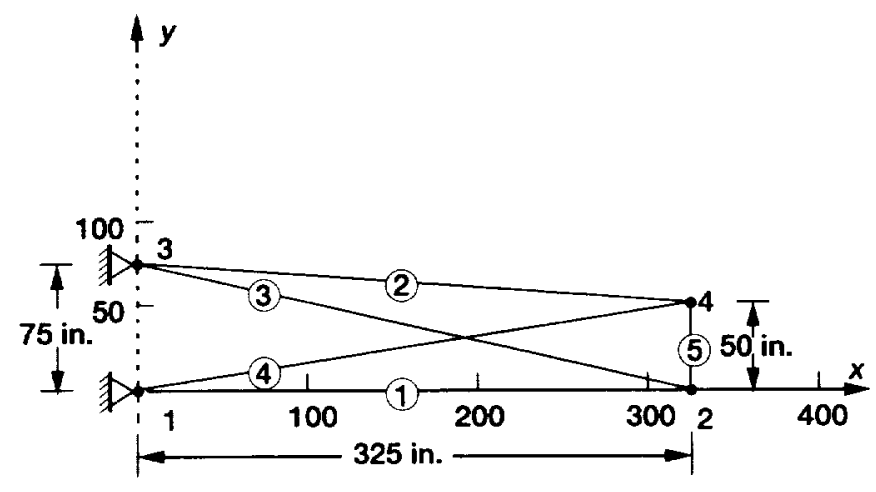

Figure 7.-Tapered five-bar truss (members are circled, nodes are not).

TABLE V.- TAPERED FIVE-BAR TRUSS DESIGN RESULTS

\begin{tabular}{|l|r|r|r|r|}
\hline Results & \multicolumn{1}{|c|}{ MFUD } & \multicolumn{1}{c|}{ FUD } & \multicolumn{1}{c|}{ SUMT } & \multicolumn{1}{c|}{ OC } \\
\hline Optimum weight, lb $^{\text {Member area, in. }}{ }^{2}$ & 6528.72 & 6549.67 & 6541.52 & 6549.02 \\
$\mathrm{~A}_{1}$ & 27.16 & 27.38 & 26.23 & 26.47 \\
$\mathrm{~A}_{2}$ & 9.37 & 9.42 & 10.37 & 10.33 \\
$\mathrm{~A}_{3}$ & 22.04 & 21.91 & 21.35 & 21.23 \\
$\mathrm{~A}_{4}$ & 11.18 & 11.27 & 11.91 & 11.97 \\
$\mathrm{~A}_{5}$ & 1.63 & 1.63 & 1.81 & 1.46 \\
Active constraints & & & & \\
Stress & 3 & --- & 2 & 3 \\
Displacement & 2 & 1 & 1 & 1 \\
\hline
\end{tabular}

\section{Example 5: Ten-Bar Truss}

The popular 10-bar truss (ref. 17) depicted in figure 1 was subjected to a single load and had 10 stress and 4 displacement constraints. Table VI summarizes the design results obtained by the four methods. MFUD produced a weight 2 percent higher than that generated by the SUMT optimizer. The design generated by the traditional FUD, however, was 13 percent heavier than the SUMT optimum design weight.

TABLE VI.-TEN-BAR TRUSS DESIGN RESULTS

\begin{tabular}{|l|r|r|r|r|}
\hline Results & \multicolumn{1}{|c|}{ MFUD } & \multicolumn{1}{c|}{ FUD } & \multicolumn{1}{c|}{ SUMT } & \multicolumn{1}{c|}{ OC } \\
\hline Optimum weight, lb & 5164.11 & 5741.21 & 5057.51 & 5061.86 \\
Member area, in. $^{2}$ & & & & \\
$\mathrm{~A}_{1}$ & 22.97 & 29.11 & 23.19 & 23.54 \\
$\mathrm{~A}_{3}$ & 0.33 & 0.36 & 0.55 & 0.53 \\
$\mathrm{~A}_{3}$ & 31.50 & 28.58 & 30.46 & 30.86 \\
$\mathrm{~A}_{8}$ & 7.43 & 20.78 & 7.43 & 7.48 \\
$\mathrm{~A}_{10}$ & 21.58 & 20.03 & 21.64 & 21.09 \\
Active constraints & & & & \\
Stress & --- & --- & 1 & ---- \\
Displacement & 2 & 1 & 2 & 2 \\
\hline
\end{tabular}

\section{Example 6: Tapered Ten-Bar Truss}

The tapered 10-bar aluminum truss (ref. 23) depicted in figure 8 was subjected to two load conditions, each with 10 stress and 4 displacement constraints. Table VII presents the design results produced by the four different methods. For this example, SQP_IMSL provided the best optimum weight; SUMT and MFUD designs were 0.1 and 0.4 percent heavier, respectively. The active constraints for MFUD, SUMT, and SQP_IMSL numbered 5, 7, and 7, respectively.

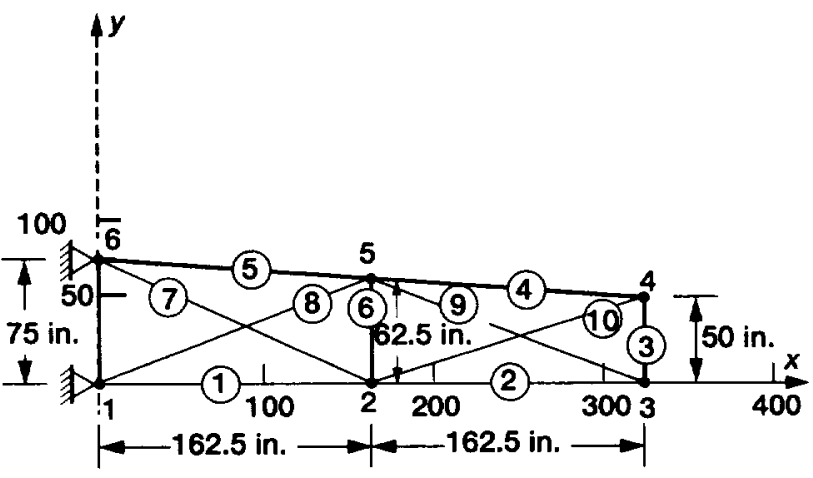

Figure 8.-Tapered ten-truss (members are circled, nodes are not).

TABLE VII. - TAPERED TEN-BAR TRUSS DESIGN RESULTS

\begin{tabular}{|l|r|r|r|r|}
\hline \multicolumn{1}{|c|}{ Results } & MFUD & \multicolumn{1}{c|}{ FUD } & \multicolumn{1}{c|}{ SUMT } & SQP_IMSL \\
\hline Optimum weight, lb & 3272.64 & 3350.60 & 3260.75 & 3258.26 \\
Member area, in. ${ }^{2}$ & & & & \\
$\mathrm{~A}_{1}$ & 58.55 & 62.49 & 55.97 & 54.91 \\
$\mathrm{~A}_{3}$ & 2.29 & 1.95 & 1.98 & 2.36 \\
$\mathrm{~A}_{5}$ & 34.87 & 35.73 & 38.25 & 40.07 \\
$\mathrm{~A}_{8}$ & 19.67 & 20.11 & 21.15 & 22.28 \\
$\mathrm{~A}_{10}$ & 5.84 & 7.27 & 6.78 & 5.29 \\
Active constraints & & & & \\
Stress & 3 & --- & 5 & 5 \\
Displacement & 2 & 1 & 2 & 2 \\
\hline
\end{tabular}

\section{Example 7: Twenty-Five-Bar Truss}

The 25-bar aluminum truss (ref. 7) in figure 9 was subjected to 2 load conditions, with 25 stress and 6 displacement constraints for each load case. The bars' areas were linked to obtain 8 independent design variables. The attributes for the optimum design for this truss are summarized in table VIII. SUMT, FD, and MFUD produced comparable optimum weights; however, the MFUD weight was 0.23 percent lighter than that of the FD optimizer. The active constraints for MFUD, SUMT, and FD were 8,6 , and 8 , respectively. The weight generated by the traditional FUD method was 6.4 percent heavier than that of the FD optimizer with a single active constraint. 


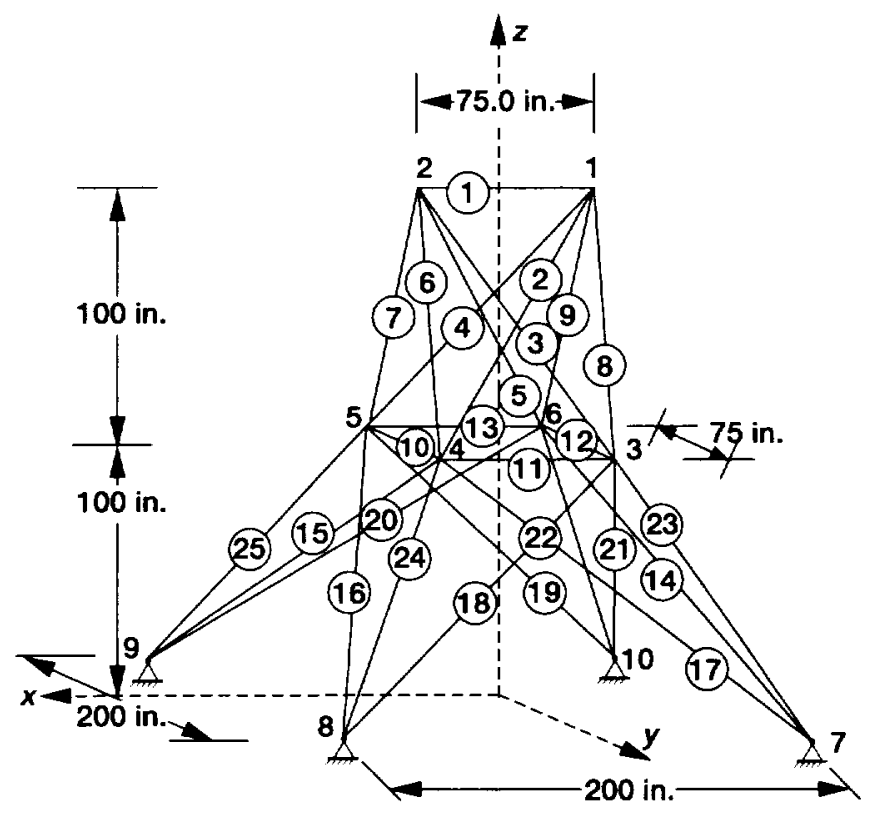

TABLE VIII-- TWENTY-FIVE-BAR TRUSS
\begin{tabular}{|l|r|r|r|r|}
\hline \multicolumn{4}{|c|}{ DESIGN RESULTS } \\
\hline Results & MFUD & \multicolumn{1}{c|}{ FUD } & \multicolumn{1}{|c|}{ SUMT } & \multicolumn{1}{c|}{ FD } \\
\hline Optimum weight, lb & 380.26 & 404.44 & 381.71 & 381.12 \\
Member area, in. ${ }^{2}$ & & & & \\
$\mathrm{~A}_{1}$ & 0.01 & 0.02 & 0.01 & 0.01 \\
$\mathrm{~A}_{3}$ & 2.07 & 2.27 & 2.06 & 2.11 \\
$\mathrm{~A}_{5}$ & 0.01 & 0.01 & 0.01 & 0.01 \\
$\mathrm{~A}_{7}$ & 1.16 & 1.34 & 1.16 & 1.17 \\
$\mathrm{~A}_{8}$ & 1.86 & 1.72 & 1.88 & 1.83 \\
Active constraints & & & & \\
Stress & 4 & --- & 2 & 4 \\
Displacement & 4 & 1 & 4 & 4 \\
\hline
\end{tabular}

Figure 9.-Twenty five-bar truss (members are circled, nodes are not).

\section{Example 8: Simply Supported Truss}

Figure 10 shows a 10-bay steel truss with 51 members subjected to a single load. All bar areas were considered independent variables. The results obtained for 51 stress and 2 midspan transverse displacement constraints are summarized in table IX. For this example, the MFUD weight lies between the optimum weights generated by the FD and SUMT optimizers.

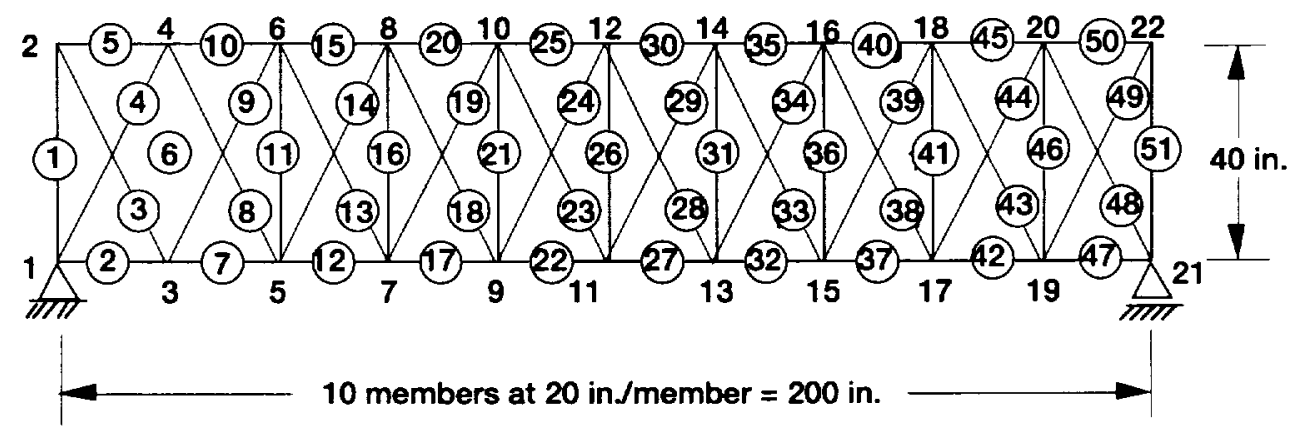

Figure 10.-Ten-bay truss (members are circled, nodes are not).

TABLE IX - SIMPLY SUPPORTED TRUSS DESIGN RESULTS

\begin{tabular}{|l|r|r|r|r|}
\hline Results & MFUD & \multicolumn{1}{c|}{ FUD } & SUMT & \multicolumn{1}{c|}{ FD } \\
\hline Optimum weight, lb $^{\text {Member area, in. }}{ }^{2}$ & 734.15 & 808.74 & 719.69 & 782.52 \\
A $_{2}$ & 2.38 & 2.73 & 2.54 & 2.68 \\
$\mathrm{~A}_{15}$ & 3.46 & 4.10 & 3.33 & 4.16 \\
$\mathrm{~A}_{25}$ & 5.46 & 6.29 & 5.73 & 5.23 \\
$\mathrm{~A}_{35}$ & 5.23 & 5.98 & 5.03 & 4.99 \\
$\mathrm{~A}_{51}$ & 1.00 & 1.23 & 1.00 & 1.93 \\
Active constraints & & & & \\
Stress & 3 & --- & 13 & 11 \\
Displacement & 2 & 2 & 2 & 2 \\
\hline
\end{tabular}




\section{Example 9: Sixty-Bar Trussed Ring}

A ring idealized by 60 bar members (ref. 23) subjected to 3 loads is depicted in figure 11. It has 60 stress and 6 displacement constraints for each load case. The 60 bars' areas were linked to obtain 25 independent design variables. Table $\mathrm{X}$ presents the optimum designs obtained for the ring. For this example, MFUD, SUMT, and FD results were in good agreement, and the active constraints for each method numbered 19,12 , and 15 , respectively.

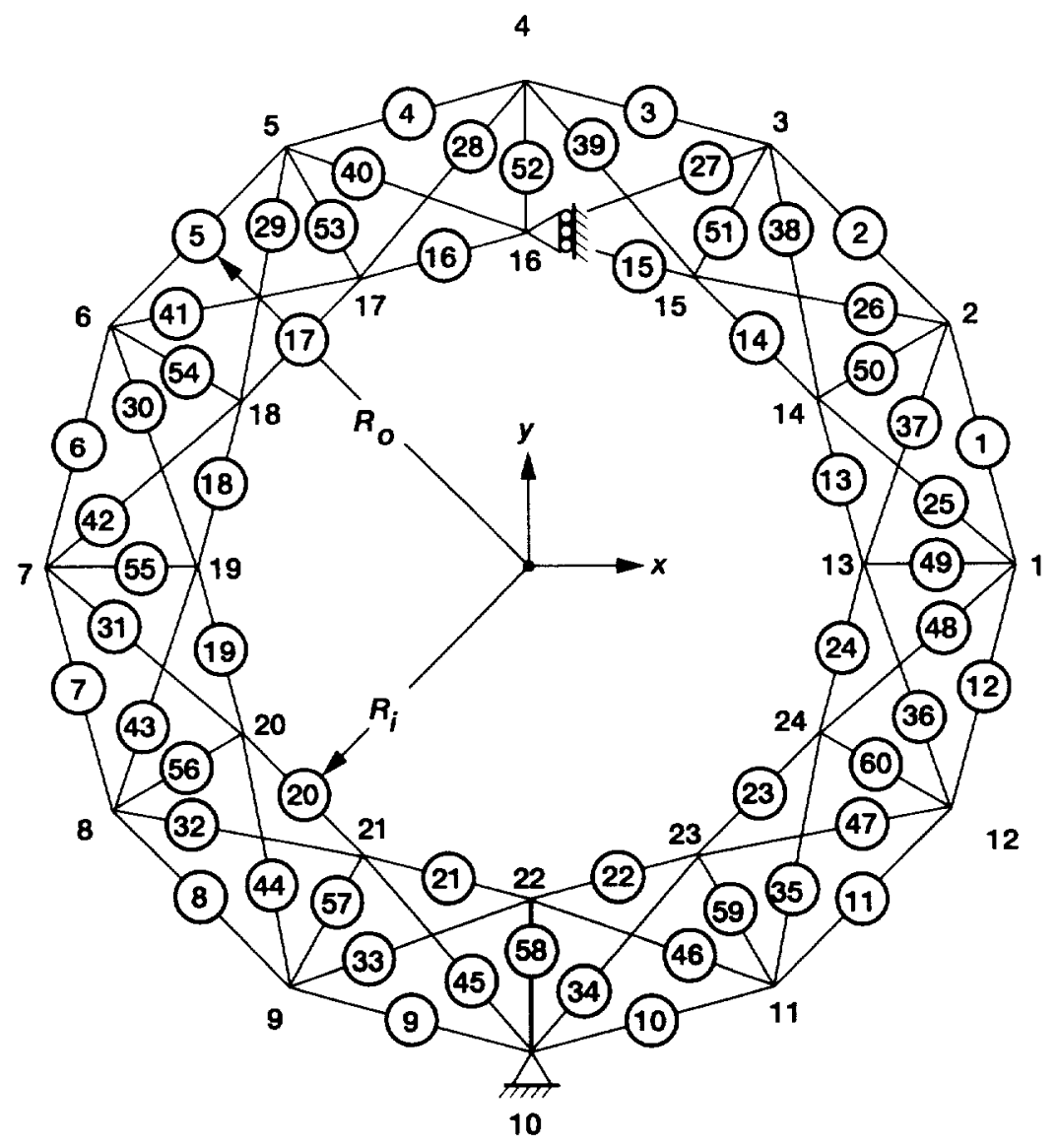

Figure 11.-Sixty-bar trussed ring (members are circled, nodes are not; $\boldsymbol{A}_{0}=$ outer radius; $\boldsymbol{R}_{i}=$ inner radius).

TABLE X-SIXTY-BAR TRUSSED RING
\begin{tabular}{|l|r|r|r|r|}
\hline \multicolumn{4}{|c|}{ DESIGN RESULTS } \\
\hline Results & MFUD & \multicolumn{1}{|c|}{ FUD } & \multicolumn{1}{l|}{ SUMT } & \multicolumn{1}{c|}{ FD } \\
\hline Optimum weight, lb $^{1308.07}$ & 324.23 & 308.96 & 308.93 \\
Member area, in. $^{2}$ & & & & \\
$\mathrm{~A}_{5}$ & 0.59 & 0.63 & 0.58 & 0.57 \\
$\mathrm{~A}_{10}$ & 1.84 & 1.61 & 1.94 & 1.85 \\
$\mathrm{~A}_{15}$ & 0.77 & 0.57 & 0.69 & 0.71 \\
$\mathrm{~A}_{20}$ & 0.97 & 1.04 & 1.07 & 1.07 \\
$\mathrm{~A}_{25}$ & 1.16 & 1.34 & 1.15 & 1.15 \\
Active constraints & & & & \\
Stress & 18 & --- & 11 & 14 \\
Displacements & 1 & 1 & 1 & 1 \\
\hline
\end{tabular}




\section{Example 10: Geodesic Dome}

An aluminum geodesic dome (ref. 17) idealized by $132 \mathrm{bar}$ members and subjected to a single load is depicted in figure 12 . The areas of the bars in the dome were linked to obtain the seven independent design variables. The designs obtained for 132 stress and 1 displacement constraint are given in table XI. For this example, the MFUD weight of $119.44 \mathrm{lb}$ was lighter than the FD weight by $5.52 \mathrm{lb}$, but heavier than the SUMT weight by $0.8 \mathrm{lb}$. The traditional FUD weight was 560 percent heavier.
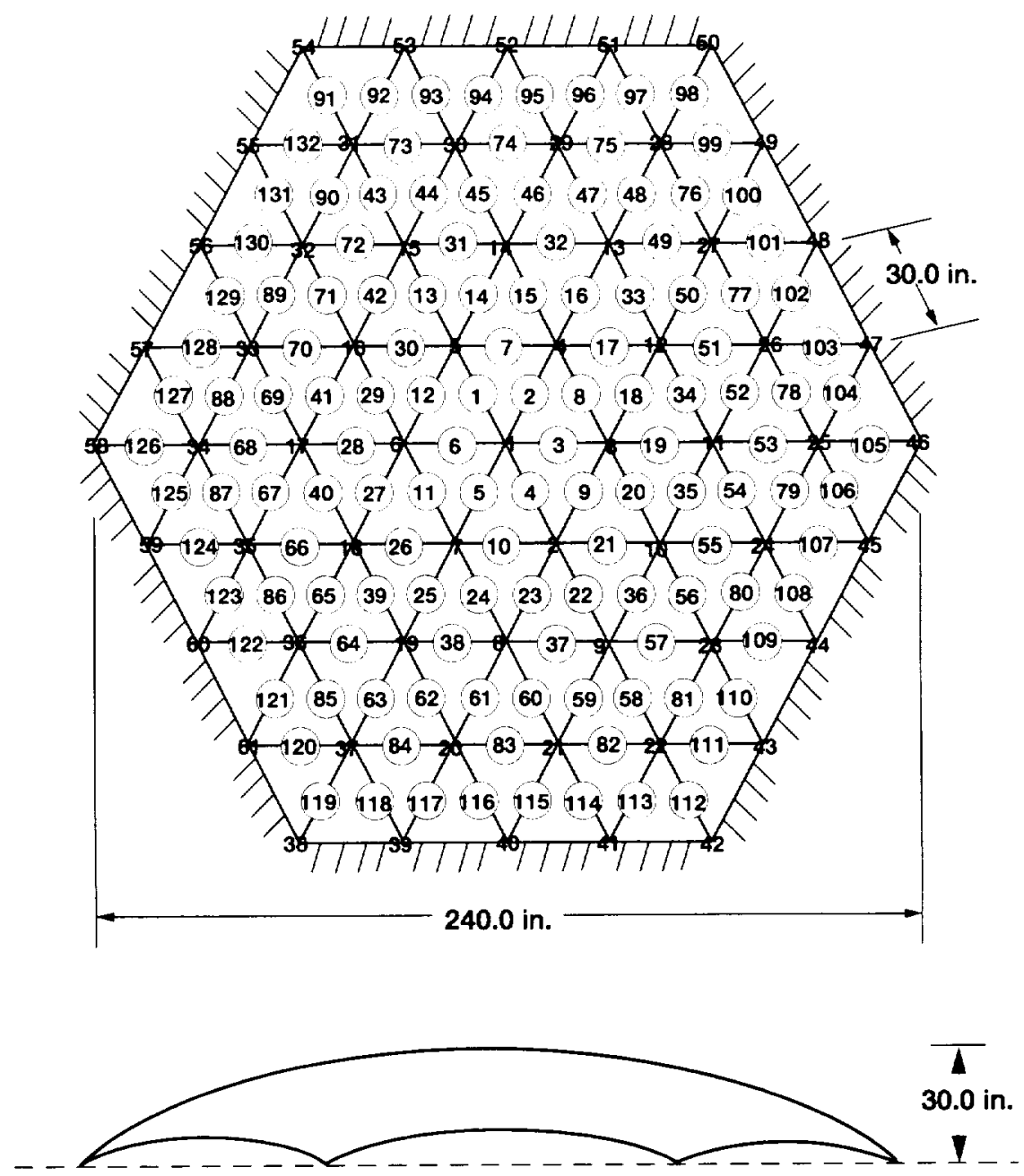

Figure 12.-Geodesic dome (members are circled, nodes are not).

TABLE XI.- GEODESIC DOME DESIGN RESULTS

\begin{tabular}{|l|r|r|r|r|}
\hline \multicolumn{1}{|c|}{ Results } & MFUD & \multicolumn{1}{c|}{ FUD } & SUMT & \multicolumn{1}{c|}{ FD } \\
\hline Optimum weight, lb $^{2}$ & 119.44 & 676.01 & 118.65 & 124.96 \\
Member area, in. $^{2}$ & & & & \\
$\mathrm{~A}_{1}$ & 0.52 & 1.68 & 0.55 & 0.90 \\
$\mathrm{~A}_{3}$ & 0.31 & 1.70 & 0.29 & 0.29 \\
$\mathrm{~A}_{5}$ & 0.29 & 1.74 & 0.29 & 0.29 \\
$\mathrm{~A}_{7}$ & 0.30 & 1.76 & 0.30 & 0.30 \\
Active constraints & & & & \\
Stress & 46 & -- & 46 & 50 \\
Displacements & 1 & 1 & 1 & 1 \\
\hline
\end{tabular}


TABLE XII.-SUMMARY OF NORMALIZED WEIGHTS

\begin{tabular}{|l|c|c|c|c|c|}
\hline \multirow{2}{*}{ Problem } & \multicolumn{5}{|c|}{ Normalized weight under- } \\
\cline { 2 - 6 } & \multicolumn{3}{|c|}{$\begin{array}{c}\text { Stress and displacement } \\
\text { constraints }\end{array}$} & $\begin{array}{c}\text { Stress constraints } \\
\text { only }\end{array}$ \\
\cline { 2 - 6 } & Optimum & MFUD & FUD & Optimum & FSD \\
\hline Three-bar truss & 1.0 & 1.00 & 1.22 & 1.0 & 1.0 \\
Five-bar truss & & 1.00 & 1.38 & -- & -- \\
Tapered five-bar truss & & 1.00 & 1.00 & 1.0 & 1.0 \\
Ten-bar truss & & 1.02 & 1.14 & $\downarrow$ & $\downarrow$ \\
Tapered ten-bar truss & & 1.00 & 1.03 & & \\
Twenty-five-bar truss & & 1.00 & 1.06 & & \\
Simply supported truss & & 1.02 & 1.12 & & \\
Sixty-bar trussed ring & & 1.00 & 1.05 & $\downarrow$ & $\downarrow$ \\
Geodesic dome & & 1.01 & 5.70 & $\downarrow$ & $\downarrow$ \\
\hline
\end{tabular}

${ }^{2}$ Normalized with respect to optimum weight obtained by SUMT.

\section{Step Length and Gradient}

Gradient and step length concepts are used differently in the MFUD method and in an optimization method. In the MFUD method, step length is a reduction factor and is assigned a value such as $t=0.5$. The factor guards against rapid change in the updated design for which analysis may no longer be valid. Step length in optimization is determined from a one-dimensional search for a profile that is contrived or assumed by using local information, including the gradient vector. The step length reduction factor in the MFUD and the step length determination in optimization are quite different. In the MFUD, the gradient information is used to separate critical design variables. This separation-and consequently gradient calculation-needs to be carried out a few times for the entire design process: for example, at initial design, at final design, and at some intermediate iterations. In optimization, gradient information is used to generate a search direction and subsequent calculations.

\section{Discussion}

Table XII summarizes the normalized weights obtained by SUMT, MFUD, and FUD for all nine examples with stress and displacement constraints. Solutions for stress constraints only were generated by using optimization and FSD methods for all the examples and are also included in table XII. From these results the following observations can be made:

(1) For stress constraints only, the FSD's generated by the stress-ratio technique are identical to the optimum designs obtained with mathematical programming techniques.
(2) For both stress and displacement constraints, designs generated by the MFUD method are in close agreement with the optimum designs-only 1 or 2 percent variation (which can largely be attributed to the values of the convergence parameter of the optimization algorithms).

(3) For stress and displacements constraints, the traditional FUD method typically produced overdesigns as expected.

\section{Concluding Remarks}

A modified fully utilized design (MFUD) method has been developed for the design of structures with both stress and displacement limitations. In the development of the MFUD method, the Integrated Force Method was found to be the appropriate analysis tool. The MFUD method has been verified through successful solutions of a number of design examples. It alleviates the overdesign limitation associated with the traditional fully utilized design method. The MFUD method has the potential to become an industrial design tool for practicing engineers, since this simple approach can generate designs comparable to those produced with design optimization methods based on difficult nonlinear mathematical programming techniques. A fully utilized design, which by definition is a design wherein the number of active constraints equal or exceed the number of design variables, represents the optimum condition. The MFUD method needs to be developed for dynamic constraints and nontruss type structures. 


\section{Appendix A}

\section{Analysis Tool for the Modified Fully Utilized Design}

Either the displacement method or the force method can be used to develop the modified fully utilized design (MFUD) technique. The IFM (integrated force method) offers certain advantages in the development of MFUD. In this appendix, the basic IFM equations are summarized, and the suitability of the IFM for design is explored.

\section{Equations of the Integrated Force Method}

In the IFM, the $n$ internal forces $\{F\}$ are considered the primary unknowns, and these can be obtained from the solution of its governing equation as follows:

$$
[S]\{F\}=\left\{P^{*}\right\}
$$

where $[\mathrm{S}]$ is the $n \times n$ governing matrix, and $\left\{P^{*}\right\}$ is the $n$-component thermomechanical load vector.

The $m$ displacement components $\{X\}$ can be obtained from the forces by back-calculation as follows:

$$
\{X\}=[J]\left\{[G]\{F\}+\{\beta\}_{0}\right\}
$$

where $[J]$ is the $m \times n$ deformation coefficient matrix $([J]=m$ rows of $\left.[S]^{-\mathrm{T}}\right),[\mathrm{G}]$ is the $n \times n$ flexibility matrix, and $\{\beta\}_{\mathrm{o}}$ is the $n$ component for the initial deformation vector.

Notice that the IFM provides two sets of equations (eqs. (20) and (21)), one for the calculation of forces and another for displacement computations. For more details on IFM, see references 14 to 16 .

\section{Equations of the Displacement Method}

The displacement vector $\{X\}$ of dimension $m$ is the primary unknown in the displacement method, and it can be obtained from its governing equation

$$
[K]\{X\}=\{P\}
$$

where $[K]$ is an $m \times m$ stiffness matrix, and $\{P\}$ is an $m$-component load vector.

Unlike the force method, the displacement method does not provide two sets of equations, one for displacements and another for forces. Instead, from nodal displacements a series of operations (such as determining the field displacement function, computing the strain by differentiation, and then calculating the stress by using Hooke's law) are carried out to determine internal forces.

\section{Suitability of Analysis Methods for Design}

The suitability of the force and the displacement methods for the development of MFUD can be illustrated by considering the example of a three-bar truss (fig. 2). The IFM governing equations for forces for the three-bar truss have the following explicit form:

$$
\left[\begin{array}{ccc}
\frac{1}{\sqrt{2}} & 0 & -\frac{1}{\sqrt{2}} \\
-\frac{1}{\sqrt{2}} & -1 & -\frac{1}{\sqrt{2}} \\
\frac{f_{1}}{\sqrt{2}} & -f_{2} & \frac{f_{3}}{\sqrt{2} k_{3}}
\end{array}\right]\left\{\begin{array}{l}
F_{1} \\
F_{2} \\
F_{3}
\end{array}\right\}=\left\{\begin{array}{c}
P_{x} \\
P_{y} \\
0
\end{array}\right\}
$$

where $F_{i}$ is the force in the ith member; $f_{i}=\left(\ell_{i} E_{i} A_{i}\right)$ is the flexibility of the $i$ th member for Young's modulus $E_{i}$, length $\ell_{i}$, and area $A_{i}$, and $P_{x}$ and $P_{y}$ are the applied load components.

The two displacement components $\left(X_{i}\right.$, for $\left.i=1,2\right)$ of the three-bar truss can be obtained from the forces by using the following equation:

$$
\begin{aligned}
&\left\{\begin{array}{l}
x_{1} \\
X_{2}
\end{array}\right\}=\frac{1}{\gamma}\left[\begin{array}{ccc}
\frac{\sqrt{2}}{f_{1}}\left(\frac{1}{f_{2}}+\frac{1}{f_{3}}\right) & \frac{1}{f_{2}}\left(\frac{1}{f_{3}}+\frac{1}{f_{1}}\right) & -\frac{\sqrt{2}}{f_{3}}\left(\frac{1}{f_{1}}+\frac{1}{f_{2}}\right) \\
-\frac{\sqrt{2}}{f_{1} f_{3}} & -\frac{\sqrt{2}}{f_{2}}\left(\frac{1}{f_{1}}+\frac{1}{f_{3}}\right) & -\frac{\sqrt{2}}{f_{1} f_{3}}
\end{array}\right] \\
& \times\left\{\begin{array}{lll}
f_{1} & 0 & 0 \\
0 & f_{2} & 0 \\
0 & 0 & f_{3}
\end{array}\right\}\left\{\begin{array}{l}
F_{1} \\
F_{2} \\
F_{3}
\end{array}\right\}
\end{aligned}
$$

where

$$
\gamma=\frac{1}{f_{1} f_{2}}+2 \frac{1}{f_{1} f_{3}}+\frac{1}{f_{2} f_{3}}
$$

Consider the design of the truss for stress limitations $\sigma_{o i}$, for $i=1,2,3$, and displacement limitations $X_{o i}$, for $i=1,2$. The two IFM equations (eqs. (24) and (25)) can be written in terms of member areas $\left(A_{1}, A_{2}, A_{3}\right)$ as follows. 
For stress limitations:

$$
\left[\begin{array}{ccc}
\frac{\sigma_{01}}{\sqrt{2}} & 0 & -\frac{\sigma_{02}}{\sqrt{2}} \\
-\frac{\sigma_{01}}{\sqrt{2}} & -\sigma_{02} & -\frac{\sigma_{03}}{\sqrt{2}} \\
\frac{\sigma_{01} f_{1}}{\sqrt{2}} & -\sigma_{02} f_{2} & \frac{\sigma_{03} f_{3}}{\sqrt{2}}
\end{array}\right]\left\{\begin{array}{l}
A_{1} \\
A_{2} \\
A_{3}
\end{array}\right\}=\left\{\begin{array}{l}
P_{x} \\
P_{y} \\
0
\end{array}\right\}
$$

For displacement limitations:

$$
\begin{gathered}
A_{1}=\frac{\ell_{1} F_{1}}{E_{1}}\left(\frac{\sqrt{2}}{X_{1}-X_{2}}\right) \\
A_{2}=\frac{\ell_{2} F_{2}}{E_{2}}\left(\frac{-1}{X_{2}}\right) \\
A_{3}=\frac{\ell_{3} F_{3}}{E_{3}}\left(\frac{-\sqrt{2}}{X_{1}+X_{2}}\right)
\end{gathered}
$$

In equation (27), if a displacement component $X_{i}$ exceeds its allowable value $X_{o i}$, then that component should be replaced by the allowable value.

An iterative solution of equations (26) and (27) can provide a design for the three-bar truss that accommodates both stress and displacement constraints. However, convergence difficulty can occur if this solution is used for more general trusses. The modified fully utilized design method developed in this paper is more suitable for such applications.

The displacement method, on the other hand, provides only two equations in terms of the three bar areas:

$$
\frac{1}{2}\left[\begin{array}{cc}
\frac{\ell_{1}}{E_{1} A_{1}}+\frac{\ell_{3}}{E_{3} A_{3}} & -\frac{\ell_{1}}{E_{1} A_{1}}+\frac{\ell_{3}}{E_{3} A_{3}} \\
-\frac{\ell_{1}}{E_{1} A_{1}}+\frac{\ell_{3}}{E_{3} A_{3}} & \frac{\ell_{1}}{E_{1} A_{1}}+2 \frac{\ell_{2}}{E_{2} A_{2}}+\frac{\ell_{3}}{E_{3} A_{3}}
\end{array}\right]\left\{\begin{array}{l}
X_{1} \\
X_{2}
\end{array}\right\}=\left\{\begin{array}{l}
P_{x} \\
P_{y}
\end{array}\right\}
$$

Even for displacement constraints only, the three areas cannot be directly determined from the solution of two stiffness equations. The stiffness formulation is not the most appropriate analysis tool to develop a direct design formulation.

\section{Displacement Sensitivities}

The $n \times m$ displacement sensitivity matrix $[\nabla X]$ required in the MFUD method can be obtained in explicit form with the IFM (ref. 19) as

$$
[\nabla X]=[[J][C][\Im]-[J][G][\mathcal{R}]]^{\top}
$$

where

$$
\begin{gathered}
{[\Im]=\operatorname{Diag} \cdot\left[F_{1}, F_{2}, \ldots, F_{n}\right]} \\
{[C]=\operatorname{Diag} \cdot\left[\frac{-\ell_{1}}{E_{1} A_{1}^{2}}, \frac{-\ell_{2}}{E_{2} A_{2}^{2}}, \ldots, \frac{-\ell_{n}}{E_{n} A_{n}^{2}}\right]} \\
{[G]=\operatorname{Diag} \cdot\left[\frac{\ell_{1}}{E_{1} A_{1}}, \frac{\ell_{2}}{E_{2} A_{2}}, \ldots, \frac{\ell_{n}}{E_{n} A_{n}}\right]} \\
{[\mathcal{R}]=[S]^{-1}\left[\frac{[0]}{[\mathrm{C}][C]}\right][\Im]}
\end{gathered}
$$

In the previous equation, Diag. designates a diagonal matrix, and $[C]$ is an $(m-n) \times n$ compatibility matrix of IFM. The first term in equation (29) accounts for changes in member flexibility, whereas the second term accounts for the changes in member forces with respect to member areas. However, Berke (ref. 9) has shown that the second term is identically equal to zero, which has also been numerically verified. The first term in equation (29) is equivalent to equation (12), which is used to develop the MFUD method. 


\section{Appendix B}

\section{Optimality of a Fully Stressed Design}

A fully stressed state is reached when all members of a truss are utilized to their full strength capabilities. Historically, such a design was considered optimum, but recently this optimality has been questioned because the weight of the structure is not used in the design calculations. This appendix examines optimality of the fully stressed design (FSD) with analytical and graphical illustrations. Solutions for a set of examples obtained by using FSD and optimization methods confirm the optimality of FSD. FSD, which can be obtained with little calculation, can be extended to displacement constraints and to nontruss-type structures.

\section{Introduction}

Researchers are baffled by two conspicuous attributes of FSD: the good numerical results obtainable with FSD; and the merit function, or weight function, of the structure, which is not taken into consideration. Optimization proponents think that FSD need not represent the optimum since the good FSD results are considered simply special cases. Practicing engineers believe that when all the members of a truss (or structure) are utilized to their full strength capabilities the design can no longer be improved. They, however, cannot offer a mathematical proof supporting the optimality of FSD. This dilemma has persisted since the sixties (refs. 1, and 24 to 28). Here, an attempt is made to alleviate the confusion. The optimality of FSD is examined in four sections: the problem is defined; optimality is discussed; numerical examples follow; and discussions and a summary are presented.

\section{Truss Design Problem}

Consider an $n$-bar truss with $n$ member areas as design variables subjected to $q$ load conditions. A fully stressed state (of FSD) is reached when each members' stress equals allowable strength $\sigma_{0}$. This design can be cast as the following mathematical programming problem: Find $n$ variables $A_{i}$ for $i=1,2, \ldots, n$ to minimize weight $W=\sum_{i=1}^{n} \rho_{i} l_{i} A_{i}$ subjected to
$n q$ stress constraints

$$
g_{i}=1-\left|\frac{\sigma_{i}}{\sigma_{0}}\right| \quad i=1,2, \ldots, n q
$$

The optimum solution-variables $\left(A_{i}^{\text {opt }}\right.$ for $\left.i=1,2, \ldots, n\right)$, minimum weight $\left(W^{o p t}\right)$, and active constraints $\left(g_{j}^{a c t}=0\right.$, $\mathrm{j}=1,2, \ldots, n)-$ can be obtained by using one of several optimization methods (see refs. 13 and 29). In optimization methods, both the weight function and the constraints participate. In FSD, only the constraints are solved iteratively to obtain the design variables, without any reference to weight. The FSD weight ( $W^{f s d}$ ) is back-calculated from the areas. That FSD need not be optimum (i.e., $A_{i}^{f s d} \neq A_{i}^{o p t}$ for $i=1,2, \ldots, n$, and $W^{f s d} \nsucceq W^{o p t}$ ) is a popular misconception.

\section{Optimality of the Fully Stressed Design}

The Lagrangian functional obtained by adjoining the active constraints to the weight function is used to examine the optimality of FSD:

$$
\mathscr{L}(\{A\},\{\lambda\})=\mathrm{W}(\{A\})+\sum_{\text {active set }} \lambda_{i} g_{i}^{*}(\{A\})
$$

where $(*)$ indicates the active constraints and $\{\lambda\}$ the multipliers. The variables and the multipliers can be obtained from its stationary condition:

$$
\begin{gathered}
\nabla W(\{A\})+\sum_{\text {active set }} \lambda_{i} \nabla g_{i}^{*}(\{A\})=\{0\} \\
g_{i}(\{A\})=\{0\} \quad\left(g_{i}^{*} \text { within the active set }\right)
\end{gathered}
$$

Equations (33) and (34) yield the optimum solution.

The optimality of FSD is considered by examining three relations between the design variables and the active constraints.

Case 1: There are more active constraints than design variables.

Case 2: There are an equal number of active constraints and design variables.

Case 3: There are fewer active constraints than design variables.

The three-bar truss (fig. 2) subjected to two load conditions, with three design variables, six stress constraints, and weight as the merit function, is used for illustration. 


\section{Case 1: More Active Constraints Than Design Variables}

Geometrical solution.-Consider an optimum solution with $n$ variables and $(n+v)$ active constraints. The optimal solution is at the intersection of any $n$ out of the $(n+v)$ active constraints. The remaining $v$ are follower constraints passing through the optimal point. For the truss with three design variables, assume an optimal design with four active constraints, $g_{1}, g_{3}, g_{5}$, and $g_{6}$ (fig. 13). Three constraints $\left(g_{3}, g_{5}\right.$, and $\left.g_{6}\right)$ are sufficient to establish the optimal point. The follower constraint $\left(g_{1}\right)$ can be neglected without any consequence. From a geometrical consideration, the inclusion of a maximum of $n$ active constraints is sufficient to establish the optimal design. The weight function is not essential when $v>0$.

Analytical solution. - The $(2 n+v)$ unknowns (being $n$ variables and $(n+v)$ multipliers) can be determined as the solution

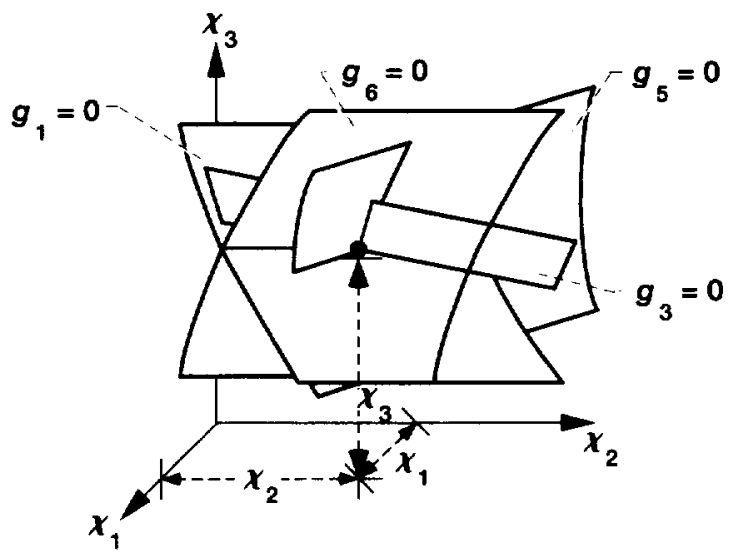

Figure 13.-Three active constraints (sufficient to determine optional point) and two follower constraints.

to equations (33) and (34). An uncoupled strategy is to solve for the $n$ design variables from any $n$ of $(n+v)$ constraint functions given by equation (34). Values for other variables and the weight function can be back-calculated. Summarizing, when active constraints exceed design variables, the optimum can be obtained from the solution of a set of $n$ active constraints.

\section{Case 2: An Equal Number of Active Constraints and Design Variables}

An optimal solution with $n$ variables and $n$ active constraints, by definition, represents a fully stressed design. The stationary condition of the Lagrangian (eqs. (33) and (34)) represent $2 n$ equations in $2 n$ unknowns. The uncoupled equation (34), being $n$ constraint equations, can be solved for the $n$ design variables. The $n$ multipliers and optimum weight can be back-calculated. For the truss, the solution of three constraints will yield the design variables. The optimum weight and the multipliers can be back-calculated from equations (31) and (34) respectively.
When the number of active constraints equal or exceed the number of design variables, the solution of the active constraints (i.e., eq. (34)) provides the design variables. The design thus obtained is both fully stressed and optimum.

\section{Case 3: Fewer Active Constraints Than Design Variables}

An optimum solution with fewer active constraints than design variables is not a fully stressed design. For the three-bar truss, assume two active constraints $\left(g_{1}\right.$ and $\left.g_{2}\right)$ given by equation (34). The two constraint equations are expressed in terms of three unknown design variables. Although equation (34) is independent of Lagrangian multipliers, it does not have sufficient quantity for a solution of the three design variables. Thus, both equations (33) and (34), which are coupled in variables, multipliers, and weight gradient, must be solved simultaneously to generate the optimum solution. The gradient of the weight function and the multipliers are required to calculate the design variables. In other words, only when the number of active constraints is fewer than the number of design variables do both the constraints and the weight function participate. Mathematical programming methods address this situation in particular. Practical truss design, however, more frequently falls under Cases 1 and 2.

\section{Design of a Truss Under a Single Load Condition}

For an indeterminate truss under a single load condition, a full stress state may not be achievable because of the compatibility condition (refs. 27, 28, and 30). Take, for example, an $n$-bar truss with $r$ redundant members. If its FSD is attempted without restricting the lower bound of the member areas, then the design will degenerate to a determinate structure that, of course, will be fully stressed and optimum. If, however, a minimum bound $A^{\text {min }}$ is specified for member areas, the resulting design will have $(n-r)$ fully stressed members with $(n-r)$ active stress constraints and $r$ member areas that reach the minimum bounds of $A^{\text {min }}$. These properties, from an analytical viewpoint, become equivalent to $n$ active constraints consisting of $(n-r)$ stress constraints and $r$ lower bound side constraints. Since there are $n$ design variables, this example falls under Case 2. In other words, the design of a truss under a single load also represents the optimum design.

A fully stressed design state can be defined in terms of two indices, Index ${ }^{\text {stress }}$ and Index ${ }^{\text {all. }}$ :

$$
\text { Index }^{\text {stress }}=\frac{\text { (number of active stress constraints) }}{\text { (number of independent design variables) }}
$$

Index $^{\text {all }}=\frac{\text { (number of active stress constraints }+ \text { number of active bounds) }}{\text { (number of independent design variables) }}$ 


$$
\text { Index }=\operatorname{maximum}\left(\text { Index }{ }^{\text {stress }}, \text { Index }^{\text {all }}\right)
$$

For analytical purposes, a fully stressed state is reached when the Index $\geq 1$.

\section{Numerical Examples}

Examples are separated into a first example and a group of problems. The first example, with several subcases, examines the role of the weight function when the number of active constraints exceed or equal the number of design variables (as in Cases 1 and 2). The second group of examples compares stressratio-based FSD's with their optimum designs. Two optimizers, SUMT (Sequential Unconstrained Minimization Technique) and IMSL (i.e., the Sequence of Quadratic Programming technique of IMSL) are used to solve examples in group 2. The figures and descriptions for the examples are not given here, but can be found in references 13 and 29 . All the examples were solved in a controlled environment on the NASA Lewis Cray Y-MP computer.

\section{Example 1}

A three-bar truss (see fig. 2) is used to illustrate that the weight function does not influence the optimum design when the number of active constraints equal or exceed the number of design variables. The truss is subjected to two load conditions and has a total of six stress constraints, three per load condition. The optimum solution for an aluminum truss with equal weight densities of $0.1 \mathrm{lb} / \mathrm{in}^{3}{ }^{3}$ for its three bars was obtained by using several optimization algorithms. The optimum solution for the problem is optimum weight $W^{\text {opt }}=133 \mathrm{lb}$; design variable $A^{o p t}=(3.29,3.99,3.32)$ in. $^{2}$; and four active stress constraints $\left(g_{1}, g_{3}, g_{5}\right.$, and $\left.g_{6}\right)$.

Fully stressed design.-The stress-ratio-based FSD produced the optimum design. The weight coefficients were changed over a wide range, from $0.1 \mathrm{lb} / \mathrm{in}^{3}$ for aluminum to $300 \mathrm{lb} / \mathrm{in} .{ }^{3}$ for a fictitious material. The design and active constraints obtained by FSD remained the same since the weight does not participate in the calculations. The FSD weight, however, was back-calculated; it is shown in table XIII.

SUMT optimizer.-Solutions for five different weights were attempted by SUMT (see table XIII). The SUMT optimizer

\section{TABLE XIII-OPTIMUM DESIGNS OF THREE-BAR TRUSS WITH \\ DIFFERENT MATERIALS \\ [Number of active constraints exceed number of design variables.]}

\begin{tabular}{|c|c|c|c|c|c|c|c|c|}
\hline Method & & $\begin{array}{l}\text { Cost } \\
\text { efficie }\end{array}$ & & $\mathbf{M e}$ & nber ar & & $\begin{array}{c}\text { Active } \\
\text { constraints }\end{array}$ & $\begin{array}{l}\text { Optimum } \\
\text { weight, lb }\end{array}$ \\
\hline FSD & $\begin{array}{c}0.1 \\
3 \\
6 \\
16 \\
1 \\
\end{array}$ & \begin{tabular}{|c|}
0.1 \\
6 \\
12 \\
13 \\
200 \\
\end{tabular} & $\begin{array}{c}0.1 \\
8 \\
18 \\
25 \\
300\end{array}$ & 3.30 & 3.99 & 3.32 & $\mathbf{g}_{1,} \mathbf{g}_{3}, \mathrm{~g}_{5}, \mathrm{~g}_{6}$ & $\begin{array}{l}1.33 \times 10^{2} \\
7.53 \times 10^{3} \\
1.60 \times 10^{4} \\
2.43 \times 10^{4} \\
2.20 \times 10^{5}\end{array}$ \\
\hline SUMT & $\begin{array}{c}0.1 \\
3 \\
6 \\
16 \\
1\end{array}$ & \begin{tabular}{|c|}
0.1 \\
6 \\
12 \\
13 \\
200
\end{tabular} & \begin{tabular}{|c|}
0.1 \\
8 \\
18 \\
25 \\
300
\end{tabular} & $\begin{array}{r}3.291 \\
3.299 \\
3.299 \\
3.298 \\
67.068\end{array}$ & \begin{tabular}{l|}
3.986 \\
3.998 \\
3.997 \\
3.998 \\
9.111
\end{tabular} & $\begin{array}{l}3.323 \\
3.299 \\
3.298 \\
3.299 \\
0.001\end{array}$ & $\mathrm{~g}_{1,} \mathrm{~g}_{3}, \mathrm{~g}_{\mathrm{g}}, \mathrm{g}_{6}$ & $\begin{array}{l}1.33 \times 10^{2} \\
7.53 \times 10^{3} \\
1.59 \times 10^{4} \\
2.43 \times 10^{4} \\
1.92 \times 10^{5}\end{array}$ \\
\hline ISML & \begin{tabular}{|c|}
0.1 \\
3 \\
6 \\
16 \\
1 \\
\end{tabular} & \begin{tabular}{|c|}
0.1 \\
6 \\
12 \\
13 \\
200 \\
\end{tabular} & $\begin{array}{c}0.1 \\
8 \\
18 \\
25 \\
300 \\
\end{array}$ & $\begin{array}{c}1.000 \\
3.299 \\
\end{array}$ & $\begin{array}{c}1.000 \\
4.000 \\
\mid\end{array}$ & $\begin{array}{c}1.000 \\
3.299 \\
\end{array}$ & $\begin{array}{c}\text { (a) } \\
g_{1}, g_{3}, g_{5}, g_{6}\end{array}$ & $\begin{array}{l}3.83 \times 10^{1} \\
7.53 \times 10^{3} \\
1.60 \times 10^{4} \\
2.43 \times 10^{4} \\
2.20 \times 10^{5}\end{array}$ \\
\hline OPTM1 & $\begin{array}{c}0.1 \\
3 \\
6 \\
16 \\
1\end{array}$ & \begin{tabular}{|c|}
0.1 \\
6 \\
12 \\
13 \\
200 \\
\end{tabular} & $\begin{array}{c}0.1 \\
8 \\
18 \\
25 \\
300\end{array}$ & $\begin{array}{l}3.313 \\
3.309 \\
3.309 \\
3.308 \\
3.300\end{array}$ & $\begin{array}{l}3.971 \\
3.963 \\
3.962 \\
3.961 \\
3.967\end{array}$ & $\begin{array}{l}3.323 \\
3.334 \\
3.335 \\
3.336 \\
3.328\end{array}$ & $\mathrm{~g}_{1}, \mathrm{~g}_{3}, \mathrm{~g}_{5}, \mathrm{~g}_{6}$ & $\begin{array}{l}1.33 \times 10^{2} \\
7.55 \times 10^{3} \\
1.60 \times 10^{4} \\
2.44 \times 10^{4} \\
2.21 \times 10^{5}\end{array}$ \\
\hline SQP & \begin{tabular}{|c|}
0.1 \\
3 \\
6 \\
16 \\
1 \\
\end{tabular} & \begin{tabular}{|c|}
0.1 \\
6 \\
12 \\
13 \\
200 \\
\end{tabular} & $\begin{array}{c}0.1 \\
8 \\
18 \\
25 \\
300 \\
\end{array}$ & $\begin{array}{l}2.335 \\
2.334 \\
2.334 \\
2.335 \\
2.335 \\
\end{array}$ & 2.503 & 2.505 & (a) & $\begin{array}{l}9.35 \times 10^{1} \\
5.32 \times 10^{3} \\
1.14 \times 10^{4} \\
1.74 \times 10^{4} \\
1.57 \times 10^{5} \\
\end{array}$ \\
\hline OPTM2 & $\begin{array}{c}0.1 \\
3 \\
6 \\
16 \\
1\end{array}$ & \begin{tabular}{|c|}
0.1 \\
6 \\
12 \\
13 \\
200 \\
\end{tabular} & $\begin{array}{c}0.1 \\
8 \\
18 \\
25 \\
300\end{array}$ & $\begin{array}{l}3.199 \\
3.501 \\
3.635 \\
3.657 \\
3.684\end{array}$ & $\begin{array}{l}2.556 \\
2.402 \\
2.353 \\
2.316 \\
2.336\end{array}$ & $\begin{array}{l}5.102 \\
4.682 \\
4.563 \\
4.467 \\
4.512\end{array}$ & $\begin{array}{l}g_{1}, g_{5} \\
(a) \\
g_{6} \\
g_{6} \\
g_{6}\end{array}$ & $\begin{array}{l}1.42 \times 10^{2} \\
8.22 \times 10^{3} \\
1.75 \times 10^{4} \\
2.71 \times 10^{4} \\
2.39 \times 10^{5}\end{array}$ \\
\hline
\end{tabular}

${ }^{a}$ No active constraints. 
TABLE XIV.-PERFORMANCE OF FULLY STRESSED DESIGN VERSUS OPTIMIZATION METHODS

\begin{tabular}{|c|c|c|c|c|c|c|c|c|c|}
\hline Problem & $\begin{array}{c}\text { Load } \\
\text { condition }\end{array}$ & $\begin{array}{l}\text { Independent } \\
\text { design } \\
\text { variables }\end{array}$ & $\begin{array}{l}\text { Design } \\
\text { method }\end{array}$ & $\begin{array}{c}\text { Normalized } \\
\text { weight }\end{array}$ & $\begin{array}{l}\text { Number of } \\
\text { active stress } \\
\text { constraints }\end{array}$ & $\begin{array}{l}\text { Number of } \\
\text { active side } \\
\text { constraints }\end{array}$ & Index $x^{\text {all }}$ & Index $x^{\text {steess }}$ & $\begin{array}{l}\text { Normalized } \\
\text { CPU time }\end{array}$ \\
\hline BAR3 & 1 & 3 & $\begin{array}{l}\text { FSD } \\
\text { IMSL } \\
\text { SUMT }\end{array}$ & $\begin{array}{l}1.000 \\
1.000 \\
1.000\end{array}$ & $\begin{array}{l}2 \\
2 \\
2\end{array}$ & $\begin{array}{l}1 \\
1 \\
1\end{array}$ & $\begin{array}{l}1.0 \\
1.0 \\
1.0\end{array}$ & $\begin{array}{r}0.667 \\
.667 \\
.667\end{array}$ & $\begin{array}{l}1.000 \\
1.596 \\
6.263\end{array}$ \\
\hline BAR5 & 2 & 5 & $\begin{array}{l}\text { FSD } \\
\text { IMSL } \\
\text { SUMT }\end{array}$ & $\begin{array}{l}1.000 \\
1.000 \\
1.000\end{array}$ & $\begin{array}{l}7 \\
7 \\
8\end{array}$ & $\begin{array}{l}0 \\
0 \\
0\end{array}$ & $\begin{array}{l}1.4 \\
1.4 \\
1.6\end{array}$ & $\begin{array}{l}1.400 \\
1.400 \\
1.600\end{array}$ & $\begin{array}{r}1.000 \\
.527 \\
1.288\end{array}$ \\
\hline BAR10 & $\overline{1}$ & 10 & $\begin{array}{l}\text { FSD } \\
\text { IMSL } \\
\text { SUMT }\end{array}$ & $\begin{array}{l}1.000 \\
1.000 \\
1.001\end{array}$ & $\begin{array}{l}6 \\
6 \\
6\end{array}$ & $\begin{array}{l}4 \\
4 \\
4\end{array}$ & $\begin{array}{l}1.0 \\
1.0 \\
1.0\end{array}$ & $\begin{array}{r}0.600 \\
.600 \\
.600\end{array}$ & $\begin{array}{l}1.000 \\
1.362 \\
2.859\end{array}$ \\
\hline$\overline{\text { BAR25 }}$ & 2 & 8 & $\begin{array}{c}\text { FSD } \\
\text { IMSL } \\
\text { SUMT }\end{array}$ & $\begin{array}{l}1.000 \\
1.000 \\
1.001\end{array}$ & $\begin{array}{l}11 \\
11 \\
11\end{array}$ & $\begin{array}{l}3 \\
3 \\
3\end{array}$ & $\begin{array}{l}1.75 \\
1.75 \\
1.75\end{array}$ & $\begin{array}{l}1.375 \\
1.375 \\
1.375\end{array}$ & $\begin{array}{r}1.000 \\
8.688 \\
14.213\end{array}$ \\
\hline DOME & 1 & 12 & $\begin{array}{l}\text { FSD } \\
\text { MMSL } \\
\text { SUMT }\end{array}$ & $\begin{array}{r}1.000 \\
.983 \\
.984\end{array}$ & $\begin{array}{l}188 \\
192 \\
192\end{array}$ & $\begin{array}{l}5 \\
5 \\
4\end{array}$ & $\begin{array}{l}16.08 \\
16.42 \\
16.33\end{array}$ & $\begin{array}{l}15.667 \\
16.000 \\
16.000\end{array}$ & $\begin{array}{r}1.000 \\
.743 \\
.740\end{array}$ \\
\hline RING_A & 3 & 25 & $\begin{array}{c}\text { FSD } \\
\text { IMSL } \\
\text { SUMT }\end{array}$ & $\begin{array}{r}1.000 \\
.999 \\
1.000\end{array}$ & $\begin{array}{l}40 \\
38 \\
38\end{array}$ & $\begin{array}{l}0 \\
0 \\
0\end{array}$ & $\begin{array}{l}1.60 \\
1.52 \\
1.52\end{array}$ & $\begin{array}{l}1.600 \\
1.520 \\
1.520\end{array}$ & $\begin{array}{r}1.000 \\
5.476 \\
13.101\end{array}$ \\
\hline RING_B & 1 & 60 & $\begin{array}{l}\text { FSD } \\
\text { IMSL } \\
\text { SUMT }\end{array}$ & $\begin{array}{l}1.000 \\
1.000 \\
1.003\end{array}$ & $\begin{array}{l}52 \\
52 \\
52\end{array}$ & $\begin{array}{r}16 \\
16 \\
8\end{array}$ & $\begin{array}{l}1.133 \\
1.133 \\
1.0\end{array}$ & $\begin{array}{r}0.867 \\
.867 \\
.867\end{array}$ & $\begin{array}{l}1.000 \\
2.882 \\
5.569\end{array}$ \\
\hline TOWER_A & 1 & 252 & $\begin{array}{c}\text { FSD } \\
\text { IMSL } \\
\text { SUMT }\end{array}$ & $\begin{array}{r}1.000 \\
.999 \\
1.000\end{array}$ & $\begin{array}{l}117 \\
117 \\
117\end{array}$ & $\begin{array}{l}135 \\
131 \\
139\end{array}$ & $\begin{array}{c}1.0 \\
.984 \\
1.016\end{array}$ & $\begin{array}{r}0.464 \\
.520 \\
.551\end{array}$ & $\begin{array}{r}1.000 \\
57.249 \\
81.442\end{array}$ \\
\hline TOWER_B & 2 & 252 & $\begin{array}{l}\text { FSD } \\
\text { IMSL } \\
\text { SUMT }\end{array}$ & $\begin{array}{l}1.000 \\
1.000 \\
1.000 \\
\end{array}$ & $\begin{array}{l}165 \\
165 \\
165 \\
\end{array}$ & $\begin{array}{l}97 \\
98 \\
99 \\
\end{array}$ & $\begin{array}{l}1.040 \\
1.044 \\
1.048 \\
\end{array}$ & $\begin{array}{r}0.655 \\
.655 \\
.655 \\
\end{array}$ & $\begin{array}{r}1.000 \\
48.031 \\
59.557 \\
\end{array}$ \\
\hline
\end{tabular}

converged to the optimum solution for the first four cases, producing the correct optimum weight and an identical set of four active constraints. For the fifth case, SUMT converged to an eccentric local optimum design with two, instead of four, active constraints.

IMSL optimizer.-This optimizer produced correct solutions for the last four cases. For the first case, no active constraints were produced and the IMSL solution wasunsatisfactory.

Table XIII also shows solutions obtained with other optimization methods. The FSD method provided successful solutions for all five cases. The success rate for optimization methods varied.

\section{Example Set 2}

Nine examples were solved by using FSD along with SUMT and IMSL optimizers. The normalized results with respect to the FSD answers are depicted in table XIV.

Consider the 25-bar truss, referred to as BAR25 in table XIV. It is subjected to two load conditions. Its 25 areas are linked to obtain eight independent variables. Since, at optimum, 11 stress constraints are active, a fully stressed state has been reached. The FSD, IMSL, and SUMT methods produced identical optimum solutions for the example with different CPU times. Optimizers IMSL and SUMT were, respectively, 10 and 18.5 times more expensive than the FSD method. Solutions to the other eight problems followed the pattern of the 25-bar truss, with minor variations.

\section{Discussion}

For a truss, if a fully stressed state can be reached (i.e., the number of active constraints exceed the number of design variables), then such a design can be handled satisfactorily with the stress-ratio-based FSD method. Optimization techniques for such problems can be computationally expensive and unnecessary.

In special circumstances a practical structural design may be associated with fewer active constraints than design variables. Such a design is likely to represent an overdesign condition, which can be alleviated by relaxing some of the nonactive constraints. If, however, there are fewer active constraints than design variables, then the design is not fully stressed; here, nonlinear programming optimization methods can be useful. For such problems the stress-ratio-based design can differ from the optimum design, especially when weight densities for truss members are different.

When the fully stressed design is extended to include displacement constraints, it is called a fully utilized design (FUD). FUD, which can produce overdesign conditions, has been modified to give a method that produces a satisfactory design for stress and displacement constraints (ref. 31).

The FUD method has been extended in reference 32 to nontruss-type structures. 




\section{Summary}

A fully stressed design is optimum when a full stress state can be achieved. At optimum, when the number of active constraints equal or exceed the number of design variables, then such a design can be obtained by simply using a stress-ratio algorithm without any consideration to the weight function. The stress ratio algorithm can produce a fully stressed design in a small fraction of the calculation time required by the design optimization methods. The fully stressed design method may have the potential for extension to nontruss-type structures and nonstress constraints.

\section{References}

1. Gallagher, R.H.: Fully Stressed Design. Optimum Structural Design, R.H. Gallagher and O.C. Zienkiewicz, eds., John Wiley \& Sons, London, 1973.

2. Thanedar, P.B., et al.: Performance of Some SQP Algorithms on Structural Design Problems-Sequential Quadratic Programming. Int. J. Numer. Meth. Eng., vol. 23, 1986, pp. 2187-2203.

3. Pshenichny, B.N.: Algorithms for the General Problem of Mathematical Programming. Kibernetica, vol. 5, 1970, pp. 20-125.

4. Wolfe, P.: Methods of Nonlinear Programming. Recent Advances in Mathematical Programming, R.L. Graves and P. Wolfe, eds., McGrawHill, New York, 1963.

5. Schittkowski, K.: On the Convergence of a Sequential Quadratic Programming Method With an Augmented Lagrangian Line Search Function. Math. Operationsforsch. und Stat., Ser. Optimiz., vol. 14, no. 2, 1983, pp. 197-216.

6. Leunberger, D.G.: Introduction to Linear and Nonlinear Programming. Addison-Wesley Pub. Co., Reading, MA, 1973.

7. Vanderplaats, G.N.; and Moses, F.: Structural Optimization by Methods of Feasible Directions. Comput. Struct., vol. 3, 1973, pp. 739-755.

8. Fiacco, A.V.; and McCormick, G.P.: Nonlinear Programming. Sequential Unconstrained Minimization Techniques, John Wiley \& Sons, New York, 1968.

9. Berke, L.: Convergence Behavior of Optimality Criteria Based Iterative Procedures. USAF AFFDL-TM-72-1-FEB, 1970.

10. Berke, L.; and Khot, N.S.: Performance Characteristics of Optimality Criteria Methods. Structural Optimization, G.I.N. Rozvany and B.L. Karihaloo, eds., Kluwer Academic Publishers, Norwell, MA, 1988.

11. Fleury, C.: An Efficient Optimality Criteria Approach to the Minimum Weight Design of Elastic Structures. Comput. Struct., vol. 11, 1980, pp. 163-173.
12. Patnaik, S.N., et al.: Performance Trend of Different Algorithms for Structural Design Optimization. NASA TM-4698, 1996.

13. Guptill, J.D., et al.: CometBoards User Manual Release 1.01., NASA TM-4537, 1996.

14. Patnaik, S.N.: An Integrated Force Method for Discrete Analysis. Int. J. Numer. Meth. Eng., vol. 6, no. 2, 1973, pp. 237-251.

15. Patnaik, S.N.; and Nagaraj, M.S.: Analysis of Continuum by the Integrated Force Method. Comput. Struct., vol. 26, 1987, pp. 899-905.

16. Patnaik, S.N.; Berke, L.; and Gallagher, R.H.: Integrated Force Method Versus Displacement Method for Finite Element Analysis. Comput. Struct., vol. 38, no. 4, 1991, pp. 377-407.

17. Berke, L.; and Khot, N.S.: Structural Optimization Using Optimality Criteria. NATO, Advanced Study Institutes Series F, vol. 27 SpringerVerlag, Berlin, 1987, pp. 271-311.

18. Berke, L.; and Khot, N.S.: Use of Optimality Criteria Methods for Large Scale Systems. AGARDSL-70, 1974.

19. Patnaik, S.N.; and Gallagher, R.H.: Gradients of Behaviour Constraints and Reanalysis via the Integrated Force Method. Int. J. Numer. Meth. Eng., vol. 23, 1986, pp. 2205-2212.

20. Miura, H.; and Schmit, L.A., Jr.: NEWSUMT-A FORTRAN Program for Inequality Constrained Function Minimization. User's Guide. NASA CR-159070, 1979.

21. International Mathematical and Statistical Library: User's Manual, Ver. 1.1. ISML, Houston, TX, 1989.

22. Vanderplaats, G.N.: DOT Users Manual, Ver. 2.0. Engineering Design Optimization, Inc., Santa Barbara, CA, 1989

23. Patnaik, S.N.; Guptill, J.D.; and Berke, L.: Merits and Limitations of Optimality Criteria Method for Structural Optimization. Int. J. Numer. Meth. Eng., vol. 38, 1995, pp. 3087-3120.

24. Kicher, T.P.: Optimum Design-Minimum Weight Versus Fully Stressed. J. Structural Div., ASCE, vol. 92, 1966, pp. 265-279.

25. Schmit, L.A.: Structural Design by Systematic Synthesis. Proceedings 2nd Conference on Electronic Computation, ASCE, 1960, pp. 105-132.

26. Razani, R.: Behavior of Fully Stressed Design of Structures and Its Relationship to Minimum Weight Design. AIAA J., vol. 3, no. 12, 1965 , pp. 2262-2268.

27. Dayaratnam, P.; and Patnaik, S.N.: Feasibility of Full Stress Design. AIAA J., vol. 7, 1969, pp. 773-774.

28. Patnaik, S.N.; and Dayaratnam, P.: Behavior and Design of Pin Connected Structures. Int. J. Numer. Meth. Eng. vol. 2, 1970, pp. 579-595.

29. Patnaik, S.N., et al.: Comparative Evaluation of Different Optimization Algorithms for Structural Design Applications. Int. Jnl. Numer. Meth. Eng., vol. 39, 1996, pp. 1761-1774.

30. Patnaik, S.N.: Behaviour of Trusses With Stress and Displacement Constraints. Comput. Struct., vol. 22, 1986, pp. 619-623.

31. Patnaik, S.N., et al.: Modified Fully Utilized Design (MFUD) Method for Stress and Displacement Constraints. Int. J. Numer. Meth. Eng., 1997.

32. Patnaik, S.N.; and Yadagiri, S.: Design for Frequency by Integrated Force Method-In Structural Vibration Analysis. Comp. Methods. Appl. Mech. Eng., vol. 16, 1978, pp. 213-230. 
Public reporting burden for this collection of information is estimated to average 1 hour per response, including the time for reviewing instructions, searching existing data sources, gathering and maintaining the data needed, and completing and reviewing the collection of informetion. Send comments regarding this burden estimate or any other aspect of this collection of intormation, including suggestions for reducing this burden, to Washington Headquarters Services, Directorate for information Operations and Reports, 1215 Jeffert Davis Highway. Suite 1204, Arlington, VA 22202-4302, and to the Office of Management and Budget, Paperwork Reduction Project (0704-0188), Washington, DC 20503.

\begin{tabular}{|l|c|c|}
\hline 1. AGENCY USE ONLY (Leave blank) & $\begin{array}{c}\text { 2. REPORT DATE } \\
\text { August } 1997\end{array}$ & $\begin{array}{c}\text { 3. REPORT TYPE AND DATES COVERED } \\
\text { Technical Memorandum }\end{array}$ \\
\hline $\begin{array}{l}\text { 4. TITLE AND SUBTTLE } \\
\text { Modified Fully Utilized Design (MFUD) Method for Stress } \\
\text { and Displacement Constraints }\end{array}$ & FUNDING NUMBERS
\end{tabular}

6. AUTHOR(S)

WU-505-63-5B

Surya Patnaik, Atef Gendy, Laszlo Berke, and Dale Hopkins

7. PERFORMING ORGANIZATION NAME(S) AND ADDRESS(ES)

8. PERforming ORgANIZATION REPORT NUMBER

National Aeronautics and Space Administration

Lewis Research Center

Cleveland, Ohio 44135-3191

E-10267

9. SPONSORINGMONITORING AGENCY NAME(S) AND ADDRESS(ES)

10. SPONSORINGMONITORING AGENCY REPORT NUMBER

National Aeronautics and Space Administration

Washington, D.C. 20546-0001

NASA TM-4743

11. SUPPLEMENTARY NOTES

Surya N. Patnaik, Ohio Aerospace Institute, 22800 Cedar Point Road, Cleveland, Ohio 44142; Atef Gendy, National Research Council-NASA Research Associate at Lewis Research Center; Laszlo Berke and Dale Hopkins, NASA Lewis Research Center. Responsible person, Laszlo Berke, organization code 5200, (216) 433-5648.

12a. DISTAIBUTIONAVAILABILTY STATEMENT

Unclassified - Unlimited

Subject Category 39

This publication is available from the NASA Center for AeroSpace Information, (301) 621-0390.

13. ABSTRACT (Maximum 200 worde)

The traditional fully stressed method performs satisfactorily for stress-limited structural design. When this method is extended to include displacement limitations in addition to stress constraints, it is known as the fully utilized design (FUD). Typically, the FUD produces an overdesign, which is the primary limitation of this otherwise elegant method. We have modified FUD in an attempt to alleviate the limitation. This new method, called the modified fully utilized design (MFUD) method, has been tested successfully on a number of designs that were subjected to multiple loads and had both stress and displacement constraints. The solutions obtained with MFUD compare favorably with the optimum results that can be generated by using nonlinear mathematical programming techniques. The MFUD method appears to have alleviated the overdesign condition and offers the simplicity of a direct, fully stressed type of design method that is distinctly different from optimization and optimality criteria formulations. The MFUD method is being developed for practicing engineers who favor traditional design methods rather than methods based on advanced calculus and nonlinear mathematical programming techniques. The Integrated Force Method (IFM) was found to be the appropriate analysis tool in the development of the MFUD method. In this paper, the MFUD method and its optimality are presented along with a number of illustrative examples.

14. SUBJECT TERMS

Fully utilized design; Force method; Optimization techniques

22

15. NUMBER OF PAGES

16. PRICE CODE

$\mathrm{A} 03$

\begin{tabular}{|c|c|}
\hline 17. SECURTYY CLASSIFICATION & 18. SECURITY CLASSIFICATION \\
OF REPORT & $\begin{array}{c}\text { OF THIS PAGE } \\
\text { Unclassified }\end{array}$
\end{tabular}

19. SECURITY CLASSIFICATION OF ABSTRACT Unclassified 